\title{
p53 plays a crucial role in endothelial dysfunction associated with hyperglycemia and ischemia
}

\author{
Short title: p53 in endothelial function
}

Masataka Yokoyama ${ }^{1}$, Ippei Shimizu ${ }^{2,3}$, Ayako Nagasawa ${ }^{2,4 *}$, Yohko Yoshida $^{2,3}$, Goro Katsuumi ${ }^{2}$, Takayuki Wakasugi ${ }^{2}$, Yuka Hayashi ${ }^{2}$, Ryutaro Ikegami ${ }^{2}$, Masayoshi Suda $^{2}$, Yusuke Ota ${ }^{2}$, Sho Okada ${ }^{1}$, Marcus Fruttiger ${ }^{5}$, Yoshio Kobayashi ${ }^{1}$, Masanori Tsuchida $^{4}$, Yoshiaki Kubota ${ }^{6}$, and Tohru Minamino ${ }^{2} * *$

${ }^{1}$ Department of Cardiovascular Medicine, Chiba University Graduate School of Medicine, Chiba 260-8670, Japan

${ }^{2}$ Department of Cardiovascular Biology and Medicine, Niigata University Graduate School of Medical and Dental Sciences, Niigata 951-8510, Japan

${ }^{3}$ Division of Molecular Aging and Cell Biology, Niigata University Graduate School of Medical and Dental Sciences, Niigata 951-8510, Japan

${ }^{4}$ Department of Thoracic and Cardiovascular Surgery, Niigata University Graduate School of Medical and Dental Sciences, Niigata 951-8510, Japan

${ }^{5}$ Institute of Ophthalmology, University College London, London EC1V 9EL, UK

${ }^{6}$ Department of Anatomy, Keio University School of Medicine, Tokyo 160-8582, Japan

Subject Terms: Vascular Biology, Endothelium/Vascular Type/Nitric Oxide, Vascular Disease

*These authors contributed equally to this work.

**Address correspondence to:

Tohru Minamino, M.D., Ph.D.

Department of Cardiovascular Biology and Medicine

Niigata University Graduate School of Medicine and Dental Sciences 
1-757 Asahimachi-dori, Chuo-ku, Niigata 951-8510, Japan

Phone: +81-25-227-2182

Fax: +81-25-227-0774

E-mail: t_minamino@yahoo.co.jp 


\section{ABSTRACT}

p53 is a guardian of the genome that protects against carcinogenesis. There is accumulating evidence that p53 is activated with aging. Such activation has been reported to contribute to various age-associated pathologies, but its role in vascular dysfunction is largely unknown. The aim of this study was to investigate whether activation of endothelial p53 has a pathological effect in relation to endothelial function. We established endothelial p53 loss-of-function and gain-of-function models by breeding endothelial-cell specific Cre mice with floxed Trp53 or floxed Mdm2/Mdm4 mice, respectively. Then we induced diabetes by injection of streptozotocin. In the diabetic state, endothelial p53 expression was markedly up-regulated and endothelium-dependent vasodilatation was significantly impaired. Impairment of vasodilatation was significantly ameliorated in endothelial p53 knockout (EC-p53 KO) mice, and deletion of endothelial p53 also significantly enhanced the induction of angiogenesis by ischemia. Conversely, activation of endothelial p53 by deleting Mdm2/Mdm4 reduced both endothelium-dependent vasodilatation and ischemia-induced angiogenesis. Introduction of p53 into human endothelial cells up-regulated the expression of phosphatase and tensin homolog (PTEN), thereby reducing phospho-eNOS levels. Consistent with these results, the beneficial impact of endothelial p53 deletion on endothelial function was attenuated in EC-p53 KO mice with an eNOS-deficient background. These results show that endothelial p53 negatively regulates endothelium-dependent vasodilatation and ischemia-induced angiogenesis, suggesting that inhibition of endothelial p53 could be a novel therapeutic target in patients with metabolic disorders.

Keywords: endothelium, nitric oxide, angiogenesis 


\section{INTRODUCTION}

p53 protein has a defensive role against the progression of DNA damage during tumorigenesis by regulating various cellular activities, including cell cycle arrest, senescence, and apoptosis. It is known that p53-mediated transcription is up-regulated by various stresses with advancing age, and activation of p53 is currently considered to be related to various age-associated pathologies [1], with activation of p53 signaling being reported in several age-associated diseases. For example, p53 expression is markedly up-regulated in the visceral fat of patients with diabetes or obese mice, promoting inflammation of adipose tissue and contributing to the development of insulin resistance [2]. It has also been reported that pressure overload activates p53 in the heart and that p53 has an important role in the development of heart failure [3]. Moreover, p53 induces mitochondrial dysfunction in mice with progressive telomere shortening by repressing peroxisome proliferator-activated receptor gamma coactivator 1, contributing to organ failure and abnormal metabolism [4].

A number of vascular cells have been reported to display a senescence-like phenotype in human atherosclerotic lesions [5, 6]. These cells exhibit functional abnormalities such as increased expression of inflammatory molecules and decreased production of nitric oxide, both of which are known to underlie the development of atherosclerosis [7]. Consistent with these findings, p53 immunoreactivity is detected in vascular cells at sites of chronic inflammation in human atheroma, while only a few p53-positive cells are found outside atherosclerotic lesions [8]. Moreover, immunoreactivity for cyclin-dependent kinase inhibitor 1 (p21) is also detected in human atheroma, but not in normal vessels, and is co-localized with p53 immunoreactivity. Progressive shortening of telomeres has been observed in human arteries, especially in atherosclerosis-prone vessels that are continuously exposed to turbulent flow [9], suggesting that increased turnover may lead to senescence of vascular cells by promoting telomere shortening. Various stimuli that promote the 
development of atherosclerosis may also accelerate senescence of vascular cells [10]. For example, a hyperglycemic state induces p53-dependent endothelial senescence by suppressing the activity of SIRT1, a mammalian homolog of Sir2 (which mediates longevity related to calorie restriction in C. elegans) [11-13]. Hyperinsulinemia occurs in diabetes, and has been reported to activate p53 signaling and promote endothelial cell senescence via constitutive activation of the Akt signaling pathway $[14,15]$. Oxidative stress is increased in various disease states, including hyperglycemia, hyperlipidemia, and hypertension, and it promotes aging of vascular cells in a p53/p21-dependent manner [16-22].

Coronary risk factors are known to cause endothelial dysfunction, which is an initial step in the development of atherosclerosis. Senescent endothelial cells exhibit various abnormalities that could result in endothelial dysfunction [5]. Forced introduction of telomere dysfunction into endothelial cells produces a dysfunctional phenotype, whereas telomere elongation by telomerase has a protective effect against senescence-induced dysfunction [5], suggesting a causative link between endothelial cell senescence and endothelial dysfunction. It has been demonstrated that endothelial p53 is activated in diabetes and that it negatively regulates glucose metabolism by modulating mitochondrial biogenesis and glucose uptake into skeletal muscle [23]. Previous ex vivo studies have demonstrated that adenoviral-mediated overexpression of p53 leads to impairment of endothelium-dependent vasodilation [24, 25]. In agreement with these reports, mice with heterozygous systemic p53 knockout exposed to a high-fat diet show improvement of endothelial function and lower circulating cholesterol levels [26]. On the other hand, endothelial-specific p53 deletion does not influence vascular function under non-diabetic conditions, although significant enhancement of neoangiogenesis has been observed in models of cardiac hypertrophy and limb ischemia [27]. It was recently reported that transplantation of human $\mathrm{CD} 34^{+}$cells with silencing of p53 improved recovery of blood flow after ischemia in diabetic mice [28]. Taking 
these findings into account, it is possible that pathophysiological stress such as hyperglycemia or ischemia initiates p53 activation in endothelial cells, leading to vascular dysfunction and impaired angiogenesis.

In the present study, we examined the role of endothelial p53 in regulation of vascular function by using various genetic mouse models. In mice with streptozotocin (STZ)-induced diabetes, endothelial p53 expression was markedly up-regulated and acetylcholine-induced vasodilatation was impaired compared with non-diabetic control mice. In addition, endothelial cell-specific deficiency of p53 significantly improved endothelial function in mice with STZ-induced diabetes, although hyperglycemia was not altered. We also found that endothelial p53 expression was markedly up-regulated in ischemic tissue, while ischemia-induced angiogenesis was enhanced when up-regulation of endothelial p53 was disrupted. Conversely, overexpression of endothelial p53 led to severe endothelial dysfunction in an ischemic limb model, as well as in diabetic mice. These results suggest that stress-induced up-regulation of endothelial p53 contributes to the development of vascular complications associated with metabolic disorders. Accordingly, inhibition of endothelial p53 activity could possibly be a novel therapeutic strategy for vascular disease.

\section{MATRIALS AND METHODS}

\section{Animal models}

All animal study protocols were approved by the Chiba University and Niigata University review board. C57BL/6 mice were purchased from SLC Japan (Shizuoka, Japan). Mice expressing Cre recombinase in endothelial cells (Tie2-Cre) were purchased from Jackson Laboratories. We then crossed Tie2-Cre mice (with a C57BL/6 background) and mice carrying floxed Trp53 alleles (with a C57BL/6 background) [29] to generate mice with endothelial cell-specific knockout of p53, which were used in this study at 12-14 weeks old. To inhibit NOS activity, we crossed endothelial cell-specific 
p53 knockout mice with eNOS knockout mice purchased from Jackson Laboratories to establish endothelial cell-specific p53/eNOS double knockout mice. We also crossed Pdgfb-Cre-ER mice (with a C57BL/6 background)[30] and mice carrying floxed Trp53 alleles, floxed $M d m 2$ alleles (with a C57BL/6 background)[31], or floxed $M d m 4$ alleles (with a C57BL/6 background)[32] to generate other endothelial cell-specific p53 knockout mice, endothelial cell-specific Mdm2 knockout mice, and endothelial cell-specific Mdm4 knockout mice, respectively. The mice carrying floxed $M d m 2$ alleles or floxed $M d m 4$ alleles were kindly provided by Professor Guillermina Lozano (The University of Texas MD Anderson Cancer Center). These mutant mice received tamoxifen (Sigma, USA) at a dose of $10 \mathrm{mg} \mathrm{kg}^{-1}$ intraperitoneally once a day for 5 days at 8 weeks of age to induce Cre-mediated recombination. We also generated endothelial cell-specific p53 or Mdm2 knockout mice by crossing VE cadherin-BAC-CreERT2 mice [33, 34] with mice carrying floxed Trp53 alleles or floxed Mdm2 alleles. Injection of tamoxifen was performed at $1 \mathrm{mg}$ daily for 5 days in VE cadherin-BAC-CreERT2-p53 KO mice or a single dose of $1 \mathrm{mg}$ in VE cadherin-BAC-CreERT2-Mdm2 KO mice. To induce diabetes, mice were given an intraperitoneal injection of streptozotocin (STZ) in $0.1 \mathrm{M}$ sodium citrate $(\mathrm{pH} 4.5)$ at a dose of $50 \mathrm{mg} / \mathrm{kg}$ daily for 5 days. At 4 weeks after STZ treatment, blood glucose levels were measured with a Gulutest Mint (Sanwakagakukenkyusyo, Japan) to confirm the induction of diabetes. To inhibit apoptosis, mice were treated with a pan-caspase inhibitor (Z-VAD-FMK at $3 \mathrm{mg} / \mathrm{kg}$ intraperitoneally every day, Biovision) dissolved in 0.1\% DMSO. Vascular reactivity assay, hind limb ischemia, vascular permeability assay, physiological analyses, and histological examination were performed as described in Detailed Methods of Online Supplement.

\section{Cell culture}

Human umbilical vein endothelial cells (HUVECs) were cultured in EBM-2 medium 
(Lonza, Switzerland) with 2\% FBS, growth factors (hEGF, hFGF-B, VEGF, and R3-IGF-1), heparin, hydrocortisone, ascorbic acid, and antibiotics (50 mg/ml gentamicin and $50 \mu \mathrm{g} / \mathrm{ml}$ amphotericin B). To examine the effects of exposure to high glucose, HUVECs were cultured for 24 hours in growth factor-free medium with 30 $\mathrm{mM}$ glucose and were harvested after stimulation with growth factors for 10 minutes. As the control, $5 \mathrm{mM}$ glucose was added to basal medium and D-mannitol was also added to adjust the osmolality. In addition, human aortic endothelial cells were purchased from Lonza (CC-2535) and were cultured according to the manufacturer's instructions.

\section{Gene transduction}

Small-interfering RNA (siRNA) targeting p53 (Invitrogen, BLOCK-iT RNAi Designer, No.1299003) or PTEN (Thermo, Primer Set PTEN Human1 (PTENHSS183790, PTENHSS183791, and PTENHSS183792)) was introduced into human endothelial cells by using Lipofectamine RNAiMax (Invitrogen) according to the manufacturer's instructions. High-titer adenoviral stocks $\left(10^{9} \mathrm{pfu}\right)$ were generated with the Adeno-X Expression System (Clontech) according to the manufacturer's instructions. In the in vitro gene transduction experiments, HUVECs were infected with the adenoviral vector encoding human p53 or LacZ (at 20 multiplicities of infection). In the in vivo gene transduction experiments, aortas of mice were infected with the adenoviral vector encoding human PTEN or LacZ $\left(10^{8}\right.$ pfu in $\left.250 \mu 1\right)$ [35]. In brief, after each mouse was anesthetized with isoflurane, the aorta was ligated at the level of the celiac artery and at the bilateral femoral arteries to create a semi-closed intravascular space. Then serum containing the adenovirus was infused into this space using a 30-guage needle, and the injection site was closed with adhesive (Aron Alpha A "Sankyo", Toagosei, Japan). The ligatures were removed after 1 hour, and the treated part of the aorta was harvested after another 1 hour. 


\section{RNA analysis}

For real-time PCR, total RNA was isolated from tissues or cells with RNAZol-B (Molecular Research Center) and complementary DNA was prepared using a QuiantiTect Reverse Transcription kit (QIAGEN). Quantitative real-time PCR was performed by using a LightCycler (Roche) with the Taqman Universal Probe Library and Light Cycler Master (Roche) according to the manufacturer's instructions. Data were analyzed by the $2^{-1 \Delta \Delta \mathrm{CT}}$ method.

\section{Western blot analysis}

Whole-cell lysates $(30-50 \mu \mathrm{g})$ were resolved by SDS polyacrylamide gel electrophoresis (PAGE). Proteins were transferred to a polyvinylidene difluoride (PVDF) membrane (Millipore) and were incubated with the primary antibodies. Immunoglobulin $\mathrm{G}$ ( $\mathrm{IgG}$ )-specific horseradish peroxidase antibodies (anti-mouse, anti-rabbit, and anti-goat; Jackson) were used as the secondary antibodies. For detection of mouse p53, a specific anti-mouse light chain antibody (Jackson) was used as the secondary antibody to avoid detecting the $\mathrm{IgG}$ heavy chain $(50 \mathrm{kDa})$. Actin was used as an equal loading control. Specific proteins were detected by the enhanced chemiluminescence method (Amersham), and quantitative analysis of protein levels was done with Image J software.

\section{Statistical analysis}

Results are shown as the mean \pm S.E.M. Differences between groups were examined by the two-tailed Student's t-test or ANOVA, followed by Bonferroni's correction or Tukey's multiple comparison test for comparison of mean values. Survival curves were calculated by the Kaplan-Meier method and were compared with the log-rank test. Some data were analyzed with repeated measures ANOVA, followed by Tukey's 
multiple comparison test. In all analyses, $\mathrm{P}<0.05$ was considered to indicate statistical significance. Statistical analyses were done with SPSS version 24 or Prism7 software.

\section{RESULTS}

\section{Endothelial p53 negatively regulates eNOS phosphorylation and impairs endothelium-dependent vasodilatation in a hyperglycemic model}

To investigate the role of p53 in regulation of endothelial function, we generated a mouse model of streptozotocin (STZ)-induced diabetes and examined vascular p53 expression. In agreement with previous reports, the expression of both p53 and its target genes, including cyclin-dependent kinase inhibitor la (Cdknla), was markedly up-regulated in the aortas of diabetic mice compared with non-diabetic mice (Fig. 1A and Supplemental Fig. 1A). It is well known that nitric oxide (NO) produced by endothelial NO synthase (eNOS) plays an important role in regulating various vascular functions, including vasodilatation, angiogenesis, and hemostasis [36-38]. Previous studies have demonstrated that phosphorylation of eNOS at serine 1179 (S1179) is important for modification of its molecular activity [39] and is modulated by several pathophysiological states, including shear stress [40] and sepsis [41]. We confirmed that S1179 phosphorylation was decreased in STZ diabetic mice (Fig. 1A). We also found that exposure of human endothelial cells (HUVEC) to high glucose reduced the phosphorylation of eNOS, while phosphorylation recovered with deletion of endothelial p53 (Fig. 1B and 1C). Incubation with high glucose also led to an increase of p53 in human aortic endothelial cells, associated with downregulation of phospho-eNOS expression (Supplemental Fig. 1B). Next, we established endothelial cell-specific p53 conditional knockout (Tie2-Cre; Trp53 $3^{\text {flox/flox }}$, Tie2-Cre-p53KO) mice and confirmed that STZ-induced up-regulation of Cdknla expression in the aorta was prevented by deletion of endothelial p53 (Supplemental Fig. 1A). To evaluate the influence of p53 activation on endothelial function, we mounted iliac arteries on a pressure myograph 
and measured vascular reactivity. Deletion of endothelial p53 led to amelioration of impaired endothelium-dependent relaxation after exposure to hyperglycemia (Fig. 1D). In contrast, there was no difference of the response to sodium nitroprusside (SNP) between Tie2-Cre-p53KO mice and control littermates (Fig. 1E), indicating that endothelial p53 has no role in regulating endothelium-independent vasodilatation. Both systolic and diastolic blood pressures were comparable between the genotypes (Fig. 1F). Changes of endothelial p53 expression did not have any influence on plasma glucose in mice with STZ-induced diabetes (Supplemental Fig. 1C). Since hematopoietic gene expression is known to be affected in the Tie2-Cre system, we established another endothelial cell-specific p53 KO mouse model by crossing VE cadherin-BAC-CreERT2 [33, 34] with Trp53 $3^{\text {flox/flox }}$ mice (VECad-Cre-p53KO mouse). When we generated STZ-induced diabetes in these mice and examined vascular function, endothelium-dependent relaxation was better in VECad-Cre-p53KO mice than in their control littermates (Fig. 1G), while the response to SNP was comparable between them (Fig. 1H). Results of the glucose tolerance test were similar in both groups of mice (Fig. 1I). These findings suggested that hyperglycemia-induced activation of endothelial p53 promotes endothelial dysfunction by reducing the phosphorylation of eNOS.

\section{p53-induced inhibition of eNOS is mediated by PTEN transactivation, contributing to diabetic endothelial dysfunction}

Endothelial p53 has been shown to decrease phosphorylation of eNOS through transactivation of phosphatase and tensin homolog (PTEN) [23]. High-glucose stimulation increased the expression of PTEN by cultured endothelial cells in a p53-dependent manner (Fig. 2A). We also confirmed that Pten expression in the aorta was increased in diabetic mice, and that this increase was diminished by endothelial-specific deletion of p53 (Fig. 2B). In agreement with the results of our in vitro experiments (Fig. 1B and 1C), phosphorylation of eNOS was markedly increased 
in the aortas of Tie2-Cre-p53KO mice after STZ treatment (Fig. 2C and 2D). To examine the influence of PTEN on eNOS activity, we injected adenovirus encoding PTEN into the aortas of Tie2-Cre-p53KO mice. We found that overexpression of PTEN markedly attenuated the increase of eNOS phosphorylation in the aortas of diabetic Tie2-Cre-p53KO mice (Fig. 2C and 2D). In human aortic endothelial cells infected with adenovirus encoding p53, administration of siRNA targeting PTEN (siPTEN) reduced PTEN expression and increased phospho-eNOS (Fig. 2E), suggesting that p53-induced inhibition of eNOS is mediated by transactivation of PTEN. To further investigate the influence of the p53/eNOS axis on endothelial function, we established Tie2-Cre-p53-eNOS double KO (Tie2-Cre; Trp53 flox/flox; eNOS $^{+-}$, Tie2-Cre; $\operatorname{Trp} 53^{\text {flox/flox }} ; \mathrm{eNOS}^{-/-}$) mice and measured the vascular reactivity of their iliac arteries after induction of diabetes. Consistent with a previous report [42], endothelium-dependent vasodilatation was weak in $\mathrm{eNOS}^{-1-}$ diabetic mice (Fig. 2F). In addition, p53 deletion did not improve endothelium-dependent vasodilatation in $\mathrm{eNOS}^{+/-}$or $\mathrm{eNOS}^{-/-}$diabetic mice (Fig. 2F). However, genetic eNOS insufficiency did not affect the vascular response to SNP (Fig. 2G). These findings suggest that hyperglycemia impairs endothelial function via the p53/PTEN/eNOS pathway.

\section{Inhibition of endothelial p53 activation enhances ischemia-induced angiogenesis}

It is widely recognized that angiogenesis is one aspect of endothelial function, and some pharmacological agents are reported to have a proangiogenic effect by activating the Akt-eNOS pathway [43]. To investigate the role of endothelial p53 in angiogenesis, we established a murine model of hind limb ischemia by unilateral femoral artery ligation. We found a significant increase of p53 and Cdknla expression in the ischemic arteries, as well as decreased eNOS phosphorylation at serine 1177 (Fig. 3A and 3B). To create the limb ischemia model, we generated inducible endothelial cell-specific p53 knockout $\left(i\right.$-EC-p53KO) mice (Pdgfb-Cre-ER; Trp53 ${ }^{\text {flox/flox }}$ ) because we wanted to exclude the 
effect of endothelial p53 deletion on vascular development. Histological analysis showed that there was a markedly larger number of capillaries in the ischemic limbs of $i$-EC-p53KO mice than control mice at 10 days after ligation (Fig. 3C and 3D). Laser Doppler imaging showed that inhibition of endothelial p53 significantly improved the recovery of blood flow after ischemia (Fig. 3E and 3F). To investigate whether eNOS contributed to the beneficial effects observed in $i$-EC-p53KO mice, we established $i$-ECp53-eNOS ${ }^{-/-}$mice (Pdgfb-Cre-ER; Trp53 ${ }^{\text {flox/flox }}$, eNOS $^{-/}$) and generated limb ischemia. We found that deletion of eNOS significantly impaired blood flow recovery in both wild-type and $i$-ECp53KO mice (Fig. 3E and 3F). Compared with $\mathrm{eNOS}^{-/-}$mice, $i$-ECp53-eNOS ${ }^{-/-}$mice showed similar impairment of blood flow recovery at 21 days after ligation, but had slightly better perfusion at 28 days (Fig. 3E and 3F), suggesting that deletion of eNOS attenuates the beneficial influence of endothelial p53 deficiency on neovascularization after ischemia.

\section{Endothelial Mdm2 deletion impairs vascular barrier function}

Under physiological conditions, p53 protein is continuously generated to monitor genomic instability and is removed by the ubiquitin/proteasome system when critical stress is absent. Mdm2 and Mdm4 play a crucial role in degradation of p53 protein, acting cooperatively as key negative regulators. Mdm2 is an E3 ubiquitin ligase that catalyzes ubiquitination of $\mathrm{p} 53$ and itself $[44,45]$. MDM4 contributes to inhibition of p53 by suppressing its transcriptional activity, and also by partnering with MDM2 to regulate p53 degradation [46]. To determine whether up-regulation of endothelial p53 is detrimental to endothelial homeostasis, we generated inducible endothelial cell-specific Mdm2 knockout (i-EC-Mdm2KO) mice (Pdgfb-Cre-ER; $\left.M d m 2^{\text {flox/flox }}\right)$. Endothelial p53 expression was dramatically increased in various organs of these mice, including the heart and skeletal muscles, by treatment with tamoxifen (Fig. 4A). Unexpectedly, $i$-EC-Mdm2KO mice developed swelling soon after 5 days of tamoxifen administration 
(Fig. 4B), and all of these animals died before day 16 (Fig. 4C). Computed tomography showed that the subcutaneous tissues were edematous and that these mice also had pleural effusion (Fig. 4D). There was no difference of cardiac function between $i$-EC-Mdm2KO mice and control littermates (Supplemental Fig. 2A). $i$-EC-Mdm2KO mice had a significantly lower serum albumin level than their littermates in spite of no difference in urine albumin (Fig. 4E and Supplemental Fig. 2B). We also found considerable amount of albumin in the pleural fluid of $i$-EC-Mdm2KO mice compared with the serum (Supplemental Fig. 2C), suggesting protein leakage in this mouse line. These results suggested that deletion of endothelial Mdm2 leads to increased vascular permeability with tissue edema and accumulation of pleural fluid. To test this hypothesis, we injected Evans blue dye (EBD) into the tail veins of these mice. Increased vascular permeability was revealed when mustard oil was applied to the ears of $i$-EC-Mdm2KO mice to enhance vascular leakage (Fig. 4F and Supplemental Fig. 2D). We also observed increased vascular leakage into the subcutaneous tissues of $i$-EC-Mdm2KO mice at 2 hours after injection of EBD (Fig. 4G). The data suggested that endothelial Mdm2 deficiency caused impairment of vascular barrier function in these mice, leading to premature death.

\section{Loss of endothelial Mdm4 induces modest up-regulation of p53}

We next generated inducible endothelial cell-specific Mdm4 knockout ( $i$-EC-Mdm4KO) mice (Pdgfb-Cre-ER; Mdm $4^{\text {flox/flox }}$ ). Loss of endothelial Mdm4 induced modest up-regulation of p53 expression (Fig. 5A), but did not cause tissue edema or lead to premature death after tamoxifen treatment (Fig. 5B). To clarify the differences of the vascular phenotype between $i$-EC-Mdm2KO and $i$-EC-Mdm4KO mice, we examined the expression of $\mathrm{p} 53$ and its downstream genes. Both $i$-EC-Mdm2KO mice and $i$-EC-Mdm4KO mice displayed a significant increase of p53 expression and transcription of Cdknla, compared with their respective littermates (Fig. 5C and 5D). 
We also noted that endothelial Mdm2 deletion up-regulated p53 and Cdknla more markedly compared with endothelial Mdm4 deletion (Fig. 5C and 5D). Expression of Bax, a target gene of p53 that induces apoptosis, was markedly up-regulated in $i$-EC-Mdm2KO mice, but not in $i$-EC-Mdm4KO mice (Fig. 5E). Consistent with these differences, the number of TUNEL-positive endothelial cells was dramatically increased in $i$-EC-Mdm2KO mice, but not in $i$-EC-Mdm4KO mice (Fig. 5F and 5G), indicating that induction of endothelial cell apoptosis was related to the premature death of $i$-EC-Mdm2KO mice. To test this hypothesis, we treated $i$-EC-Mdm2KO mice with a pan-caspase inhibitor Z-VAD-FMK and examined the effect on survival. Although premature death was not prevented completely, we found that administration of Z-VAD-FMK significantly extended the survival of $i$-EC-Mdm2KO mice (Fig. 5H), suggesting that endothelial cell apoptosis partly accounted for their premature death.

\section{Overexpression of p53 by Mdm4 deletion impairs endothelial function}

We next examined the impact of p53 overexpression on endothelial function by using $i$-EC-Mdm4KO mice. In agreement with our data obtained in Tie2-Cre-p53 KO mice, eNOS phosphorylation was significantly decreased in $i$-EC-Mdm4KO mice (Fig. 6A and 6B). Acetylcholine-induced vasodilatation was markedly impaired in the iliac arteries of $i$-EC-Mdm4KO mice compared with control littermates (Fig. 6C), whereas there was no difference of the response to SNP between the two groups (Fig. 6D). Laser Doppler imaging revealed that recovery of blood flow after induction of hind limb ischemia was reduced in $i$-EC-Mdm4KO mice (Fig. 6E). To further investigate the role of p53 in vascular function, we established another endothelial cell-specific Mdm2 KO mouse model by breeding VEcadherin-BAC-CreERT2 mice with $M d m 2^{\text {flox/flox }}$ mice (VECad-Cre-Mdm2KO), and we created hind limb ischemia in this model. We previously reported that VECad-Cre-Mdm2KO mice did not develop an edematous phenotype when we used a low dose of tamoxifen [34]. After creation of hind limb 
ischemia, we found that recovery of blood flow was significantly reduced in VECad-Cre-Mdm2KO mice compared with littermate controls (Fig. 6F). However, systolic and diastolic blood pressures were comparable between the two genotypes (Fig. 6G). Based on these results, p53 overexpression leads to endothelial dysfunction.

\section{DISCUSSION}

In the present study, we demonstrated that p53 overexpression had a pathological influence on endothelial function. Combined with the recent report that endothelial p53 deletion does not affect endothelium-dependent vasodilation in the non-diabetic state [27], our data indicate that p53 activation induced by metabolic stress is critically involved in vascular pathology. It is known that p53 has a central role in repair of DNA damage, acting as a gatekeeper that protects against tumor development [1]. Activation of p53 induced by DNA damage initially promotes DNA repair and cell cycle arrest, but then causes irreversible growth arrest and cellular senescence if repair fails. Constitutive activation of this signaling pathway accelerates the accumulation of senescent cells in various tissues [47, 48], and elimination of senescent cells improves various age-associated phenotypes including atherosclerosis [49-53], confirming the hypothesis that accumulation of senescent cells is critically involved in the pathology of aging and age-associated diseases.

Genetic analysis has revealed a potential relationship between p53 codon 72 polymorphism and susceptibility to coronary artery disease in humans [54-56]. Histological analysis of human atherosclerotic samples has also suggested a pathological role of p53 in the development of atherosclerosis [5, 7, 57-60]. Moreover, animal studies have demonstrated that activation of p53 in vascular cells is associated with progression of atherogenesis [61-65]. Furthermore, it was reported that deletion of $\mathrm{p} 21$, one of the transcriptional targets of $\mathrm{p} 53$, delays the progression of atherosclerosis in mice $[16,66]$. In contrast, systemic deletion of p53 in apolipoprotein E knockout 
(ApoE KO) mice results in accelerated atherosclerosis, presumably due to increased cell proliferation and a decrease of cell death [67-69]. Systemic absence of p53 also leads to accelerated neointimal growth after vascular injury, associated with increased cell proliferation and reduced apoptosis in the intima [70, 71]. Likewise, deletion of p53 in macrophages stimulates the proliferation of these cells and attenuates apoptosis, leading to larger lesions with a vulnerable phenotype [72-74]. Conversely, introduction of p53 into vessels via adenoviral infection inhibits the migration and proliferation of vascular cells, thereby reducing intima formation [75]. Using Super-p53 mice with one extra allele of the p53 gene on an ApoE KO background, Sanz-González et al. demonstrated that increasing the p53 gene dosage led to less intimal thickening after vascular injury, but had no effect on native atherosclerosis [76]. In contrast, our present results indicated that deletion of endothelial p53 had a beneficial impact on vascular function. How can we reconcile these inconsistent findings? One possible explanation is that p53 plays differing roles in vascular pathology in a cell type-dependent manner. For example, deletion of p53 in macrophages may promote the development of vulnerable plaque by increasing necrotic core formation, while deletion of p53 in endothelial cells and vascular smooth muscle cells may promote plaque stabilization by thickening the fibrous cap. Consistent with this concept, vascular smooth muscle cell-specific telomere dysfunction has been reported to increase atherosclerosis and necrotic core formation, whereas inhibition of the senescence of these cells increases the fibrous cap area and decreases the necrotic core area [77]. Another possibility is that p53 activation induces various cellular fates depending upon the cause and extent of its activation, thus having variable impacts on vascular pathology. Thus, it is postulated that p53-induced senescence has a pathological influence, but p53-induced cell death/reversible cell cycle arrest may have a protective effect on vascular disease. This idea is supported by the fact that development of atherosclerosis was markedly inhibited by deletion of p21, a negative regulator of cell cycle progression that mediates p53-dependent senescence. 
It was reported that p53 overexpression suppresses endothelium-dependent vasodilation $[24,25]$, while inhibition of p53 results in amelioration of endothelial dysfunction [26]. However, the mechanisms underlying these changes have not been fully explored. In the present study, we demonstrated that p53-induced downregulation of PTEN reduces eNOS activity, leading to impairment of endothelium-dependent vasodilatation. These results are consistent with a previous report that upregulation of endothelial p53 expression by a high fat diet led to decreased phosphorylation of eNOS by transactivation of Pten [23]. In a model of dietary obesity, TNF- $\alpha$ was found to upregulate PTEN expression, leading to suppression of the Akt/eNOS/NO signaling pathway [78]. Since p53 signaling upregulates various pro-inflammatory molecules, including TNF- $\alpha$ [2], p53-induced inflammation may also contribute to vascular dysfunction in the diabetic state.

To establish mice with endothelial cell-specific p53 knockout, we utilized three Cre transgenic models (Tie2-Cre, Pdgfb-Cre-ER, and VEcadherin-BAC-CreER mice). Because the Tie2-Cre system also affects gene expression in hematopoietic cells, most of the previous studies were conducted with bone marrow transplantation, but irradiation before transplantation would also affect the vascular phenotype. Pdgfb-Cre is another system for generating endothelial cell-specific knockout mice [79], but the genetic profile of smooth muscle cells can also be affected. For these reasons, we attempted to confirm our main findings by using the VEcadherin-BAC-CreER system [33]. VEcadherin-BAC-CreERT2 is a tamoxifen-inducible system designed for genetic modulation of endothelial cells. Similar to Tie2-Cre-p53KO $\left(\operatorname{Tie}^{2} \mathrm{Cre}^{+/-} ; \operatorname{Trp} 53^{\text {flox/flox }}\right)$ mice, genetic suppression of endothelial p53 in VECad-Cre-Mdm2KO $\left(\right.$ VECad-CreER $\left.^{+-} ; \quad \operatorname{Trp} 53^{\text {flox/flox }}\right)$ mice resulted in improvement of endothelium-dependent vasodilation in mice with STZ-induced diabetes. We also generated VECad-Cre-Mdm2KO (VECad-CreER ${ }^{+-} ; M d m 2^{\text {flox/flox }}$ ) mice as another endothelial p53 gain-of-function model, and found that recovery of blood flow after 
ischemia was impaired in these mice, providing further evidence that p53 has a critical role in vascular function.

In conclusion, we demonstrated that inhibition of endothelial p53 improved vascular dysfunction caused by metabolic stress or ischemia. Because direct inhibition of p53 could promote tumorigenesis, development of anti-senescence therapy that somehow avoids this risk is required.

\section{Sources of Funding}

This work was supported by a Grant-in-Aid for Scientific Research (Grant number 17H04172, 25870127), a Grant-in-Aid for Scientific Research on Innovative Areas (Stem Cell Aging and Disease, Grant number 26115008), and a Grant-in-Aid for Exploratory Research from the Ministry of Education, Culture, Sports, Science and Technology (MEXT, Grant number 15K15306) of Japan and grants from the Takeda Medical Research Foundation, the Japan Foundation for Applied Enzymology, the Takeda Science Foundation, the SENSHIN Medical Research Foundation, the Terumo Foundation, the Manpei Suzuki Diabetes Foundation, the Naito Foundation, and the NOVARITIS foundation (to T.M.) and by a grant from Bourbon (to T.M., Y.Y. and I.S).

\section{Disclosures}

The authors declare no conflicts of interest. 


\section{REFERENCES}

[1] K.H. Vousden, D.P. Lane, p53 in health and disease, Nat Rev Mol Cell Biol 8(4) (2007) 275-83.

[2] T. Minamino, M. Orimo, I. Shimizu, T. Kunieda, M. Yokoyama, T. Ito, A. Nojima, A. Nabetani, Y. Oike, H. Matsubara, F. Ishikawa, I. Komuro, A crucial role for adipose tissue p53 in the regulation of insulin resistance, Nat Med 15(9) (2009) 1082-7.

[3] M. Sano, T. Minamino, H. Toko, H. Miyauchi, M. Orimo, Y. Qin, H. Akazawa, K. Tateno, Y. Kayama, M. Harada, I. Shimizu, T. Asahara, H. Hamada, S. Tomita, J.D. Molkentin, Y. Zou, I. Komuro, p53-induced inhibition of Hif-1 causes cardiac dysfunction during pressure overload, Nature 446(7134) (2007) 444-8.

[4] E. Sahin, S. Colla, M. Liesa, J. Moslehi, F.L. Muller, M. Guo, M. Cooper, D. Kotton, A.J. Fabian, C. Walkey, R.S. Maser, G. Tonon, F. Foerster, R. Xiong, Y.A. Wang, S.A. Shukla, M. Jaskelioff, E.S. Martin, T.P. Heffernan, A. Protopopov, E. Ivanova, J.E. Mahoney, M. Kost-Alimova, S.R. Perry, R. Bronson, R. Liao, R. Mulligan, O.S. Shirihai, L. Chin, R.A. DePinho, Telomere dysfunction induces metabolic and mitochondrial compromise, Nature 470(7334) (2011) 359-65.

[5] T. Minamino, H. Miyauchi, T. Yoshida, Y. Ishida, H. Yoshida, I. Komuro, Endothelial cell senescence in human atherosclerosis: role of telomere in endothelial dysfunction, Circulation 105(13) (2002) 1541-4. [6] E. Vasile, Y. Tomita, L.F. Brown, O. Kocher, H.F. Dvorak, Differential expression of thymosin beta-10 by early passage and senescent vascular endothelium is modulated by VPF/VEGF: evidence for senescent endothelial cells in vivo at sites of atherosclerosis, Faseb J 15(2) (2001) 458-66.

[7] T. Minamino, T. Yoshida, K. Tateno, H. Miyauchi, Y. Zou, H. Toko, I. Komuro, Ras induces vascular smooth muscle cell senescence and inflammation in human atherosclerosis, Circulation 108(18) (2003) 2264-9.

[8] C. Ihling, G. Menzel, E. Wellens, J.S. Monting, H.E. Schaefer, A.M. Zeiher, Topographical association between the cyclin-dependent kinases inhibitor P21, p53 accumulation, and cellular proliferation in human atherosclerotic tissue, Arterioscler Thromb Vasc Biol 17(10) (1997) 2218-24.

[9] E. Chang, C.B. Harley, Telomere length and replicative aging in human vascular tissues, Proc Natl Acad Sci U S A 92(24) (1995) 11190-4.

[10] T. Minamino, I. Komuro, Vascular cell senescence: contribution to atherosclerosis, Circ Res 100(1) (2007) 15-26.

[11] M. Orimo, T. Minamino, H. Miyauchi, K. Tateno, S. Okada, J. Moriya, I. Komuro, Protective Role of SIRT1 in Diabetic Vascular Dysfunction, Arterioscler Thromb Vasc Biol (2009).

[12] G. Arunachalam, S.M. Samuel, I. Marei, H. Ding, C.R. Triggle, Metformin modulates hyperglycaemia-induced endothelial senescence and apoptosis through SIRT1, Br J Pharmacol 171(2) (2014) 523-35.

[13] E. Zhang, Q. Guo, H. Gao, R. Xu, S. Teng, Y. Wu, Metformin and Resveratrol Inhibited High Glucose-Induced Metabolic Memory of Endothelial Senescence through SIRT1/p300/p53/p21 Pathway, 
PLoS One 10(12) (2015) e0143814.

[14] H. Miyauchi, T. Minamino, K. Tateno, T. Kunieda, H. Toko, I. Komuro, Akt negatively regulates the in vitro lifespan of human endothelial cells via a p53/p21-dependent pathway, The EMBO journal 23(1) (2004) 212-20.

[15] H. Matsui-Hirai, T. Hayashi, S. Yamamoto, K. Ina, M. Maeda, H. Kotani, A. Iguchi, L.J. Ignarro, Y. Hattori, Dose-dependent modulatory effects of insulin on glucose-induced endothelial senescence in vitro and in vivo: a relationship between telomeres and nitric oxide, J Pharmacol Exp Ther 337(3) (2011) 591-9.

[16] T. Kunieda, T. Minamino, J. Nishi, K. Tateno, T. Oyama, T. Katsuno, H. Miyauchi, M. Orimo, S. Okada, M. Takamura, T. Nagai, S. Kaneko, I. Komuro, Angiotensin II induces premature senescence of vascular smooth muscle cells and accelerates the development of atherosclerosis via a p21-dependent pathway, Circulation 114(9) (2006) 953-60.

[17] L.J. Min, M. Mogi, K. Tamura, J. Iwanami, A. Sakata, T. Fujita, K. Tsukuda, F. Jing, M. Iwai, M. Horiuchi, Angiotensin II type 1 receptor-associated protein prevents vascular smooth muscle cell senescence via inactivation of calcineurin/nuclear factor of activated T cells pathway, J Mol Cell Cardiol 47(6) (2009) 798-809.

[18] L.J. Min, M. Mogi, J. Iwanami, J.M. Li, A. Sakata, T. Fujita, K. Tsukuda, M. Iwai, M. Horiuchi, Angiotensin II type 2 receptor deletion enhances vascular senescence by methyl methanesulfonate sensitive 2 inhibition, Hypertension 51(5) (2008) 1339-44.

[19] K.E. Herbert, Y. Mistry, R. Hastings, T. Poolman, L. Niklason, B. Williams, Angiotensin II-mediated oxidative DNA damage accelerates cellular senescence in cultured human vascular smooth muscle cells via telomere-dependent and independent pathways, Circ Res 102(2) (2008) 201-8.

[20] J. Chen, S.V. Brodsky, D.M. Goligorsky, D.J. Hampel, H. Li, S.S. Gross, M.S. Goligorsky, Glycated collagen I induces premature senescence-like phenotypic changes in endothelial cells, Circ Res 90(12) (2002) 1290-8.

[21] S.V. Brodsky, O. Gealekman, J. Chen, F. Zhang, N. Togashi, M. Crabtree, S.S. Gross, A. Nasjletti, M.S. Goligorsky, Prevention and reversal of premature endothelial cell senescence and vasculopathy in obesity-induced diabetes by ebselen, Circ Res 94(3) (2004) 377-84.

[22] W.Q. Liu, Y.Z. Zhang, Y. Wu, J.J. Zhang, T.B. Li, T. Jiang, X.M. Xiong, X.J. Luo, Q.L. Ma, J. Peng, Myeloperoxidase-derived hypochlorous acid promotes ox-LDL-induced senescence of endothelial cells through a mechanism involving beta-catenin signaling in hyperlipidemia, Biochem Biophys Res Commun 467(4) (2015) 859-65.

[23] M. Yokoyama, S. Okada, A. Nakagomi, J. Moriya, I. Shimizu, A. Nojima, Y. Yoshida, H. Ichimiya, N. Kamimura, Y. Kobayashi, S. Ohta, M. Fruttiger, G. Lozano, T. Minamino, Inhibition of endothelial p53 improves metabolic abnormalities related to dietary obesity, Cell Rep 7(5) (2014) 1691-703.

[24] C.S. Kim, S.B. Jung, A. Naqvi, T.A. Hoffman, J. DeRicco, T. Yamamori, M.P. Cole, B.H. Jeon, K. 
Irani, p53 impairs endothelium-dependent vasomotor function through transcriptional upregulation of p66shc, Circulation research 103(12) (2008) 1441-50.

[25] A. Kumar, C.S. Kim, T.A. Hoffman, A. Naqvi, J. Dericco, S.B. Jung, Z. Lin, M.K. Jain, K. Irani, p53 impairs endothelial function by transcriptionally repressing Kruppel-Like Factor 2, Arterioscler Thromb Vasc Biol 31(1) (2011) 133-41.

[26] F. Leblond, S. Poirier, C. Yu, N. Duquette, G. Mayer, E. Thorin, The anti-hypercholesterolemic effect of low p53 expression protects vascular endothelial function in mice, PLoS One 9(3) (2014) e92394.

[27] R. Gogiraju, X. Xu, M.L. Bochenek, J.H. Steinbrecher, S.E. Lehnart, P. Wenzel, M. Kessel, E.M. Zeisberg, M. Dobbelstein, K. Schafer, Endothelial p53 Deletion Improves Angiogenesis and Prevents Cardiac Fibrosis and Heart Failure Induced by Pressure Overload in Mice, Journal of the American Heart Association 4(2) (2015).

[28] N. Kundu, C.C. Domingues, C. Chou, N. Ahmadi, S. Houston, D.J. Jerry, S. Sen, Use of p53-Silenced Endothelial Progenitor Cells to Treat Ischemia in Diabetic Peripheral Vascular Disease, Journal of the American Heart Association 6(4) (2017).

[29] S. Marino, M. Vooijs, H. van Der Gulden, J. Jonkers, A. Berns, Induction of medulloblastomas in p53-null mutant mice by somatic inactivation of $\mathrm{Rb}$ in the external granular layer cells of the cerebellum, Genes Dev 14(8) (2000) 994-1004.

[30] S. Claxton, V. Kostourou, S. Jadeja, P. Chambon, K. Hodivala-Dilke, M. Fruttiger, Efficient, inducible Cre-recombinase activation in vascular endothelium, Genesis 46(2) (2008) 74-80.

[31] J.D. Grier, W. Yan, G. Lozano, Conditional allele of mdm2 which encodes a p53 inhibitor, Genesis 32(2) (2002) 145-7.

[32] J.D. Grier, S. Xiong, A.C. Elizondo-Fraire, J.M. Parant, G. Lozano, Tissue-specific differences of p53 inhibition by Mdm2 and Mdm4, Mol Cell Biol 26(1) (2006) 192-8.

[33] K. Okabe, S. Kobayashi, T. Yamada, T. Kurihara, I. Tai-Nagara, T. Miyamoto, Y.S. Mukouyama, T.N. Sato, T. Suda, M. Ema, Y. Kubota, Neurons Limit Angiogenesis by Titrating VEGF in Retina, Cell 159(3) (2014) 584-596.

[34] S. Si, Y. Nakajima-Takagi, T. Iga, M. Tsuji, L. Hou, M. Oshima, S. Koide, A. Saraya, S. Yamazaki, K. Takubo, Y. Kubota, T. Minamino, A. Iwama, Hematopoietic insults damage bone marrow niche by activating p53 in vascular endothelial cells, Exp Hematol 63 (2018) 41-51 e1.

[35] M.Y. Alexander, M.J. Brosnan, C.A. Hamilton, P. Downie, A.M. Devlin, F. Dowell, W. Martin, H.M. Prentice, T. O'Brien, A.F. Dominiczak, Gene transfer of endothelial nitric oxide synthase improves nitric oxide-dependent endothelial function in a hypertensive rat model, Cardiovascular research 43(3) (1999) 798-807.

[36] S. Moncada, A. Higgs, The L-arginine-nitric oxide pathway, The New England journal of medicine 329(27) (1993) 2002-12.

[37] T. Murohara, T. Asahara, M. Silver, C. Bauters, H. Masuda, C. Kalka, M. Kearney, D. Chen, J.F. 
Symes, M.C. Fishman, P.L. Huang, J.M. Isner, Nitric oxide synthase modulates angiogenesis in response to tissue ischemia, The Journal of clinical investigation 101(11) (1998) 2567-78.

[38] Y. Ohashi, S. Kawashima, K. Hirata, T. Yamashita, T. Ishida, N. Inoue, T. Sakoda, H. Kurihara, Y. Yazaki, M. Yokoyama, Hypotension and reduced nitric oxide-elicited vasorelaxation in transgenic mice overexpressing endothelial nitric oxide synthase, The Journal of clinical investigation 102(12) (1998) 2061-71.

[39] S. Dimmeler, I. Fleming, B. Fisslthaler, C. Hermann, R. Busse, A.M. Zeiher, Activation of nitric oxide synthase in endothelial cells by Akt-dependent phosphorylation, Nature 399(6736) (1999) 601-5.

[40] R.S. Scotland, M. Morales-Ruiz, Y. Chen, J. Yu, R.D. Rudic, D. Fulton, J.P. Gratton, W.C. Sessa, Functional reconstitution of endothelial nitric oxide synthase reveals the importance of serine 1179 in endothelium-dependent vasomotion, Circulation research 90(8) (2002) 904-10.

[41] L. Connelly, M. Madhani, A.J. Hobbs, Resistance to endotoxic shock in endothelial nitric-oxide synthase (eNOS) knock-out mice: a pro-inflammatory role for eNOS-derived no in vivo, The Journal of biological chemistry 280(11) (2005) 10040-6.

[42] D.N. Atochin, A. Wang, V.W. Liu, J.D. Critchlow, A.P. Dantas, R. Looft-Wilson, T. Murata, S. Salomone, H.K. Shin, C. Ayata, M.A. Moskowitz, T. Michel, W.C. Sessa, P.L. Huang, The phosphorylation state of eNOS modulates vascular reactivity and outcome of cerebral ischemia in vivo, The Journal of clinical investigation 117(7) (2007) 1961-7.

[43] A. Brouet, P. Sonveaux, C. Dessy, S. Moniotte, J.L. Balligand, O. Feron, Hsp90 and caveolin are key targets for the proangiogenic nitric oxide-mediated effects of statins, Circulation research 89(10) (2001) 866-73.

[44] Y. Haupt, R. Maya, A. Kazaz, M. Oren, Mdm2 promotes the rapid degradation of p53, Nature 387(6630) (1997) 296-9.

[45] M.H. Kubbutat, S.N. Jones, K.H. Vousden, Regulation of p53 stability by Mdm2, Nature 387(6630) (1997) 299-303.

[46] S. Francoz, P. Froment, S. Bogaerts, S. De Clercq, M. Maetens, G. Doumont, E. Bellefroid, J.C. Marine, Mdm4 and Mdm2 cooperate to inhibit p53 activity in proliferating and quiescent cells in vivo, Proc Natl Acad Sci U S A 103(9) (2006) 3232-7.

[47] T. Minamino, I. Komuro, Vascular aging: insights from studies on cellular senescence, stem cell aging, and progeroid syndromes, Nat Clin Pract Cardiovasc Med 5(10) (2008) 637-48.

[48] I. Shimizu, Y. Yoshida, M. Suda, T. Minamino, DNA damage response and metabolic disease, Cell Metab 20(6) (2014) 967-77.

[49] D.J. Baker, T. Wijshake, T. Tchkonia, N.K. LeBrasseur, B.G. Childs, B. van de Sluis, J.L. Kirkland, J.M. van Deursen, Clearance of p16Ink4a-positive senescent cells delays ageing-associated disorders, Nature 479(7372) (2011) 232-6.

[50] D.J. Baker, B.G. Childs, M. Durik, M.E. Wijers, C.J. Sieben, J. Zhong, R.A. Saltness, K.B. 
Jeganathan, G.C. Verzosa, A. Pezeshki, K. Khazaie, J.D. Miller, J.M. van Deursen, Naturally occurring p16(Ink4a)-positive cells shorten healthy lifespan, Nature 530(7589) (2016) 184-9.

[51] M. Xu, A.K. Palmer, H. Ding, M.M. Weivoda, T. Pirtskhalava, T.A. White, A. Sepe, K.O. Johnson, M.B. Stout, N. Giorgadze, M.D. Jensen, N.K. LeBrasseur, T. Tchkonia, J.L. Kirkland, Targeting senescent cells enhances adipogenesis and metabolic function in old age, Elife 4 (2015) e12997.

[52] C.M. Roos, B. Zhang, A.K. Palmer, M.B. Ogrodnik, T. Pirtskhalava, N.M. Thalji, M. Hagler, D. Jurk, L.A. Smith, G. Casaclang-Verzosa, Y. Zhu, M.J. Schafer, T. Tchkonia, J.L. Kirkland, J.D. Miller, Chronic senolytic treatment alleviates established vasomotor dysfunction in aged or atherosclerotic mice, Aging Cell 15(5) (2016) 973-7.

[53] J. Chang, Y. Wang, L. Shao, R.M. Laberge, M. Demaria, J. Campisi, K. Janakiraman, N.E. Sharpless, S. Ding, W. Feng, Y. Luo, X. Wang, N. Aykin-Burns, K. Krager, U. Ponnappan, M. Hauer-Jensen, A. Meng, D. Zhou, Clearance of senescent cells by ABT263 rejuvenates aged hematopoietic stem cells in mice, Nat Med 22(1) (2016) 78-83.

[54] F. Gloria-Bottini, M. Banci, P. Saccucci, P. Nardi, M. Scognamiglio, F. Papetti, A. Magrini, A. Pellegrino, E. Bottini, L. Chiariello, p53 codon 72 polymorphism and coronary artery disease: evidence of association with left ventricular ejection fraction, Am J Med Sci 343(2) (2012) 127-30.

[55] P. Saccucci, M. Banci, A. Amante, E. Bottini, F. Gloria-Bottini, Coronary artery disease: evidence of interaction between PTPN22 and p53 genetic polymorphisms, Cardiology 120(3) (2011) 166-8.

[56] F. Gloria-Bottini, M. Banci, P. Saccucci, A. Neri, E. Bottini, A. Magrini, p53 codon 72 polymorphism and coronary artery disease: evidence of interaction with ACP(1), Med Sci Monit 18(12) (2012) CR712-5.

[57] C. Ihling, J. Haendeler, G. Menzel, R.D. Hess, G. Fraedrich, H.E. Schaefer, A.M. Zeiher, Co-expression of p53 and MDM2 in human atherosclerosis: implications for the regulation of cellularity of atherosclerotic lesions, J Pathol 185(3) (1998) 303-12.

[58] A.M. Lavezzi, J. Milei, D.R. Grana, F. Flenda, A. Basellini, L. Matturri, Expression of c-fos, p53 and PCNA in the unstable atherosclerotic carotid plaque, Int J Cardiol 92(1) (2003) 59-63.

[59] V.G. Gorgoulis, H. Pratsinis, P. Zacharatos, C. Demoliou, F. Sigala, P.J. Asimacopoulos, A.G. Papavassiliou, D. Kletsas, p53-dependent ICAM-1 overexpression in senescent human cells identified in atherosclerotic lesions, Lab Invest 85(4) (2005) 502-11.

[60] A. Varela, C. Piperi, F. Sigala, G. Agrogiannis, C.H. Davos, M.A. Andri, C. Manopoulos, S. Tsangaris, E.K. Basdra, A.G. Papavassiliou, Elevated expression of mechanosensory polycystins in human carotid atherosclerotic plaques: association with p53 activation and disease severity, Sci Rep 5 (2015) 13461.

[61] S. Xiong, G. Salazar, N. Patrushev, M. Ma, F. Forouzandeh, L. Hilenski, R.W. Alexander, Peroxisome proliferator-activated receptor gamma coactivator-1alpha is a central negative regulator of vascular senescence, Arterioscler Thromb Vasc Biol 33(5) (2013) 988-98. 
[62] C.M. Warboys, A. de Luca, N. Amini, L. Luong, H. Duckles, S. Hsiao, A. White, S. Biswas, R. Khamis, C.K. Chong, W.M. Cheung, S.J. Sherwin, M.R. Bennett, J. Gil, J.C. Mason, D.O. Haskard, P.C. Evans, Disturbed flow promotes endothelial senescence via a p53-dependent pathway, Arterioscler Thromb Vasc Biol 34(5) (2014) 985-95.

[63] S. Xiong, N. Patrushev, F. Forouzandeh, L. Hilenski, R.W. Alexander, PGC-1alpha Modulates Telomere Function and DNA Damage in Protecting against Aging-Related Chronic Diseases, Cell Rep 12(9) (2015) 1391-9.

[64] T.K. Ito, M. Yokoyama, Y. Yoshida, A. Nojima, H. Kassai, K. Oishi, S. Okada, D. Kinoshita, Y. Kobayashi, M. Fruttiger, A. Aiba, T. Minamino, A crucial role for CDC42 in senescence-associated inflammation and atherosclerosis, PLoS One 9(7) (2014) e102186.

[65] Y. Xiong, Y. Yu, J.P. Montani, Z. Yang, X.F. Ming, Arginase-II induces vascular smooth muscle cell senescence and apoptosis through p66Shc and p53 independently of its 1-arginine ureahydrolase activity: implications for atherosclerotic plaque vulnerability, J Am Heart Assoc 2(4) (2013) e000096.

[66] A.J. Merched, L. Chan, Absence of p21Waf1/Cip1/Sdi1 modulates macrophage differentiation and inflammatory response and protects against atherosclerosis, Circulation 110(25) (2004) 3830-41.

[67] N.V. Guevara, H.S. Kim, E.I. Antonova, L. Chan, The absence of p53 accelerates atherosclerosis by increasing cell proliferation in vivo, Nat Med 5(3) (1999) 335-9.

[68] J. Mercer, N. Figg, V. Stoneman, D. Braganza, M.R. Bennett, Endogenous p53 protects vascular smooth muscle cells from apoptosis and reduces atherosclerosis in ApoE knockout mice, Circ Res 96(6) (2005) 667-74.

[69] V.I. Sayin, O.M. Khan, L.E. Pehlivanoglu, A. Staffas, M.X. Ibrahim, A. Asplund, P. Agren, A. Nilton, G. Bergstrom, M.O. Bergo, J. Boren, P. Lindahl, Loss of one copy of Zfp148 reduces lesional macrophage proliferation and atherosclerosis in mice by activating p53, Circ Res 115(9) (2014) 781-9.

[70] M. Sata, K. Tanaka, N. Ishizaka, Y. Hirata, R. Nagai, Absence of p53 leads to accelerated neointimal hyperplasia after vascular injury, Arterioscler Thromb Vasc Biol 23(9) (2003) 1548-52.

[71] M. Moroi, T. Izumida, T. Morita, J. Tatebe, C. Ishii, T. Imai, S. Yagi, T. Yamaguchi, S. Katayama, Effect of p53 deficiency on external vascular cuff-induced neointima formation, Circ J 67(2) (2003) 149-53.

[72] B.J. van Vlijmen, G. Gerritsen, A.L. Franken, L.S. Boesten, M.M. Kockx, M.J. Gijbels, M.P. Vierboom, M. van Eck, B. van De Water, T.J. van Berkel, L.M. Havekes, Macrophage p53 deficiency leads to enhanced atherosclerosis in APOE*3-Leiden transgenic mice, Circ Res 88(8) (2001) 780-6.

[73] A.J. Merched, E. Williams, L. Chan, Macrophage-specific p53 expression plays a crucial role in atherosclerosis development and plaque remodeling, Arterioscler Thromb Vasc Biol 23(9) (2003) 1608-14.

[74] L.S. Boesten, A.S. Zadelaar, A. van Nieuwkoop, L. Hu, A.F. Teunisse, A.G. Jochemsen, B. Evers, B. van de Water, M.J. Gijbels, B.J. van Vlijmen, L.M. Havekes, M.P. de Winther, Macrophage p53 controls 
macrophage death in atherosclerotic lesions of apolipoprotein E deficient mice, Atherosclerosis 207(2) (2009) 399-404.

[75] S.J. George, G.D. Angelini, M.C. Capogrossi, A.H. Baker, Wild-type p53 gene transfer inhibits neointima formation in human saphenous vein by modulation of smooth muscle cell migration and induction of apoptosis, Gene Ther 8(9) (2001) 668-76.

[76] S.M. Sanz-Gonzalez, L. Barquin, I. Garcia-Cao, M. Roque, J.M. Gonzalez, J.J. Fuster, M.T. Castells, J.M. Flores, M. Serrano, V. Andres, Increased p53 gene dosage reduces neointimal thickening induced by mechanical injury but has no effect on native atherosclerosis, Cardiovasc Res 75(4) (2007) 803-12.

[77] J. Wang, A.K. Uryga, J. Reinhold, N. Figg, L. Baker, A. Finigan, K. Gray, S. Kumar, M. Clarke, M. Bennett, Vascular Smooth Muscle Cell Senescence Promotes Atherosclerosis and Features of Plaque Vulnerability, Circulation 132(20) (2015) 1909-19.

[78] R.M. da Costa, K.B. Neves, F.L. Mestriner, P. Louzada, T. Bruder-Nascimento, R.C. Tostes, TNF-alpha induces vascular insulin resistance via positive modulation of PTEN and decreased Akt/eNOS/NO signaling in high fat diet-fed mice, Cardiovasc Diabetol 15 (2016).

[79] K. Wilhelm, K. Happel, G. Eelen, S. Schoors, M.F. Oellerich, R. Lim, B. Zimmermann, I.M. Aspalter, C.A. Franco, T. Boettger, T. Braun, M. Fruttiger, K. Rajewsky, C. Keller, J.C. Bruning, H. Gerhardt, P. Carmeliet, M. Potente, FOXO1 couples metabolic activity and growth state in the vascular endothelium, Nature 529(7585) (2016) 216-20. 


\section{Figure Legends}

Figure 1 Endothelial p53 deletion ameliorates decreased phosphorylation of eNOS and endothelial dysfunction under hyperglycemia

(A) Expression of p53, phospho-eNOS, and eNOS in the aortas of mice was examined by western blotting after administration of the vehicle (vehicle) or streptozotocin (STZ). (B) Human umbilical vein endothelial cells (HUVECs) transfected with siRNA targeting p53 (sip53) or control siRNA (siControl) were exposed to high glucose (High Glu) for 24 hours. Then expression of p53, phospho-eNOS, and eNOS was examined by western blot analysis. (C) Quantitative analysis of eNOS phosphorylation in HUVECs prepared as in Figure 1B (n=3). (D) Endothelium-dependent vasorelaxation in the iliac arteries of Tie2-Cre-p53KO (Tie2Cre ${ }^{+-} ; \operatorname{Trp} 53^{\text {flox/flox }}$ mice) and littermate controls (Control, Trp5 $3^{\text {flox/flox }}$ mice) treated with the vehicle or STZ $(n=4)$. Control-vehicle vs. Control-STZ (**P < 0.01); Control-STZ vs. Tie2-Cre-p53KO-STZ ( $\left.{ }^{\#} \mathrm{P}<0.05\right)$. (E) Endothelium-independent vasodilation of iliac arteries. (F) Systolic blood pressure $(\mathrm{sBP})$ and diastolic blood pressure $(\mathrm{dBP})$ of the indicated mice. $(\mathrm{G}, \mathrm{H})$ Endothelium-dependent $(\mathrm{G})$ or independent $(\mathrm{H})$ vasodilation in the iliac arteries of VECad-Cre-p53KO (VECad-CreER ${ }^{+-} ; \operatorname{Trp} 53^{\text {flox/flox }}$ ) mice and littermate controls (Control, Trp53 $3^{\text {flox/flox }}$ mice) treated with the vehicle or STZ $(\mathrm{n}=3,5,5,5)$. Control-vehicle vs. Control-STZ (**P < 0.01), Control-STZ vs. VECad-Cre-p53KO-STZ ( $\left.{ }^{\#} \mathrm{P}<0.05\right)$. (I) Intraperitoneal glucose tolerance test (GTT) performed in the indicated mice $(n=5,3)$. Data were analyzed by the two-tailed Student's t-test (F), 2-way ANOVA followed by Bonferroni's correction (C), or repeated measures ANOVA followed by Tukey's multiple comparison test $(\mathrm{D}, \mathrm{E}, \mathrm{G}-\mathrm{I}) . * \mathrm{P}<0.05$; $* * \mathrm{P}<0.01$, ***P $<0.001$. Values represent the mean \pm SEM. NS = not significant.

Figure 2 p53-induced inhibition of eNOS is mediated by PTEN transactivation, contributing to diabetic endothelial dysfunction 
(A) Real-time PCR for expression of PTEN in HUVECs prepared as in Figure 1B $(n=3)$.

(B) Real-time PCR for expression of Pten in the aortas of mice prepared as in Figure 1D $(\mathrm{n}=3)$. (C) Expression of PTEN, phospho-eNOS, and eNOS was examined by western blotting in the aortas of Tie2-Cre-p53KO mice and littermate controls (Control) infected with adenovirus encoding LacZ (Ad-LacZ) or PTEN (Ad-PTEN) (D) Quantitative analysis of the eNOS phosphorylation study shown in Figure $2 \mathrm{C}(\mathrm{n}=3)$. (E) In human aortic endothelial cells (HAEC) infected with adeno-p53 and co-administered siRNA targeting PTEN (siPTEN), expression of p53, PTEN, phospho-eNOS (p-eNOS), and eNOS was examined by western blotting. Right panel indicates quantification $(n=5,4)$. One abnormal value ( $\mathrm{n}=1$ in siPTEN group) was excluded by box plot analysis (SPSS) before further analysis of the data. (F, G) Endothelium-dependent (F) or -independent (G) vasodilation of iliac arteries after STZ treatment in Control-eNOS ${ }^{+/}$, Tie2-Cre-p53KO-eNOS $^{+-}$, Control-eNOS ${ }^{--}$and Tie2-Cre-p53KO-eNOS ${ }^{-/}$mice $(n=4,3,3,3)$. Data were analyzed by the two-tailed Student's t-test (E), 2-way ANOVA followed by Bonferroni's correction (A, B, D), or repeated measures ANOVA followed by Tukey's multiple comparison test $(\mathrm{F}, \mathrm{G}) .{ }^{*} \mathrm{P}<0.05$; $* * \mathrm{P}<0.01$, $* * * \mathrm{P}<0.001$. Values represent the mean \pm SEM. NS = not significant.

\section{Figure 3 Inhibition of endothelial p53 activation enhances ischemia-induced angiogenesis}

(A) Expression of p53, phospho-eNOS, and eNOS was examined by western blotting in murine femoral arteries at sham and ischemic sites. The proximal femoral artery and distal popliteal artery were ligated, and the arteries were stripped out after 24 hours. (B) Real-time PCR for expression of Cdkn1a (p21) in the femoral arteries of mice prepared as in Figure 3A $(\mathrm{n}=3)$. (C) Immunostaining for Isolectin B4 (green) in ischemic quadriceps muscles of i-EC-p53KO (Pdgfb-Cre-ER ${ }^{+-}$; $\left.\operatorname{Trp} 53^{\text {flox/flox }}\right)$ mice and littermate 
controls (Control) on day 10. Scale bar $=100 \mu \mathrm{m}$. (D) The number of capillaries per muscle fiber was examined in the ischemic limbs shown in Figure 3C. $(n=4$, 3HPF/mouse). (E) Laser Doppler perfusion imaging of hind limb ischemia in Control, i-EC-p53KO, Control-eNOS ${ }^{-/}$, and i-EC-p53KO-eNOS ${ }^{--}$mice on day 7. (F) Blood flow recovery was analyzed by laser Doppler perfusion imaging at the indicated time points $\quad(\mathrm{n}=6) \quad\left(\right.$ Control vs Control-eNOS ${ }^{--} \quad(\dagger \dagger \dagger+\mathrm{P}<0.0001)$, i-EC-p53KO vs. i-EC-p53KO-eNOS ${ }^{-/-}(\# \# \#$ P<0.0001), Control vs i-EC-p53KO $(* \mathrm{p}<0.05))$. Data were analyzed by the two-tailed Student's t-test (B, D) or repeated measures ANOVA followed by Tukey's multiple comparison test $(\mathrm{F}) . * \mathrm{P}<0.05 ; * * \mathrm{P}<0.01$, *** $\mathrm{P}<0.001$. Values represent the mean \pm SEM. NS $=$ not significant.

\section{Figure 4 Endothelial Mdm2 deletion increases vascular permeability, leading to}

\section{fatal systemic edema}

(A) Immunohistochemistry for p53 (brown) of arteries in the heart and skeletal muscle of i-EC-Mdm2KO (Pdgfb-Cre-ER ${ }^{+/} ; M d m 2^{\text {flox/flox }}$ ) mice and littermate controls $\left(M d m 2^{\text {flox/flox }}\right)$. Scale bar $=50 \mu \mathrm{m}$. Black arrows in the high magnification view (High Mag) indicate p53-positive endothelial cells. (B) An i-EC-Mdm2KO mouse and an

$M d m 2^{\text {flox/flox }}$ mouse at 10 days after tamoxifen-induced gene deletion. (C) Kaplan-Meier analysis of the survival of i-EC-Mdm2KO mice and $M d m 2^{\text {flox/flox }}$ mice after tamoxifen-induced gene deletion ( $n=5)$. (D) CT of the mice in Figure 4B. (E) Serum albumin levels of the mice in Figure 4B (n=3). (F) Vascular permeability was assessed from Evans blue dye (EBD) leakage in the ear lobes of i-EC-Mdm2KO mice and $M d m 2^{\text {flox/flox }}$ mice after tamoxifen-induced gene deletion $(n=3) .(G)$ EBD leakage into the skin of the mice shown in Figure 4F. The Kaplan-Meier method and log-rank test were used for survival analysis. (C). Data were analyzed by the two-tailed Student's t-test $(\mathrm{E}, \mathrm{F}) . * \mathrm{P}<0.05 ; * * \mathrm{P}<0.01, * * * \mathrm{P}<0.001$. Values represent the mean \pm SEM. $\mathrm{NS}=$ not significant 


\section{Figure 5 Loss of endothelial Mdm4 induces modest up-regulation of p53}

(A) Immunohistochemistry for p53 (brown) of arteries in the skeletal muscle of i-EC-Mdm4KO (Pdgfb-Cre-ER $\left.{ }^{+/-} ; M d m 4^{\text {flox/flox }}\right)$ mice and littermate controls $\left(M d m 4^{\text {flox/flox }}\right)$. Scale bar $=50 \mu \mathrm{m}$. Black arrows in the high magnification view (High Mag) indicate p53-positive endothelial cells. (B) An i-EC-Mdm4KO mouse and an $M d m 4^{\text {flox/flox }}$ mouse at 10 days after tamoxifen-induced gene deletion. (C) Expression of p53 examined by western blot analysis in the lungs of $M d m 2^{\text {flox/flox }}$ mice, i-EC-Mdm2KO mice, Mdm $4^{\text {flox/flox }}$ mice, and i-EC-Mdm4KO mice. The p53protein level was calculated after correction by the actin level $(n=4)$. (D, E) Real-time PCR for expression of Cdknla (p21) (D) and Bax (E) in lungs prepared as in Figure 5C (n=3-4). (F) Immunostaining for Isolectin B4 (Red) and TUNEL staining (Green) of vessels in skeletal muscles prepared as in Figure 5C. Scale bar $=20 \mu \mathrm{m}$. White arrows indicate TUNEL-positive endothelial cells. (G) The number of TUNEL-positive endothelial cells was counted in the skeletal muscles prepared as in Figure 5F, and the percentage was calculated as the ratio to total endothelial cells ( $\mathrm{n}=3-4,2-4 \mathrm{HFP} / \mathrm{mouse})$. (H) Kaplan-Meier analysis of survival in $\mathrm{i}-\mathrm{EC}-\mathrm{Mdm} 2 \mathrm{KO}$ mice and $M d m 2^{\text {flox/flox }}$ mice treated with the pan-caspase inhibitor Z-VAD-FMK or DMSO (control) after tamoxifen-induced gene deletion $(\mathrm{n}=5-6) . \quad * * \mathrm{P}<0.01, \quad M d m 2^{\text {flox/flox }}$ DMSO vs. i-EC-Mdm2KO DMSO; $\dagger \dagger \mathrm{P}<0.01, M d m 2^{\text {flox/flox }}$ Z-VAD-FMK vs. i-EC-Mdm2KO Z-VAD-FMK; \#P<0.05, i-EC-Mdm2KO DMSO vs. i-EC-Mdm2KO Z-VAD-FMK. The Kaplan-Meier method and log-rank test were used for survival analysis. (H). Data were analyzed by 2-way ANOVA followed by Bonferroni's correction $(\mathrm{C}-\mathrm{E}, \mathrm{G}),{ }^{*} \mathrm{P}<0.05$; $* * \mathrm{P}<0.01, * * * \mathrm{P}<0.001$. Values represent the mean \pm SEM. NS $=$ not significant.

Figure 6 Endothelial p53 overexpression by Mdm4 deletion impairs endothelial function and ischemia-induced angiogenesis 
(A) Expression of phospho-eNOS (p-eNOS) and eNOS was examined by western blotting in the aortas of $M d m 4^{\text {flox/flox }}$ mice and i-EC-Mdm4KO (Pdgfb-Cre-ER ${ }^{+/}$; $M d m 4^{\text {flox/flox }}$ mice. (B) Quantitative analysis of eNOS phosphorylation in aorta prepared as in Figure 6A (n=3). (C, D) Endothelium-dependent $(C)(n=4)$ or independent $(D)(n=4)$ vasorelaxation of iliac arteries. Mice were prepared as in Figure $6 A(n=4)$. $(E$, F) Blood flow recovery was analyzed by laser Doppler perfusion imaging at the indicated time points after induction of hind limb ischemia in $M d m 4^{\text {flox/flox }}$ mice and i-EC-Mdm4KO mice $(\mathrm{n}=6) \quad(\mathrm{E})$, or $M d m 2^{\text {flox/flox }}$ and VECad-Cre-Mdm2KO $\left(\right.$ VECad-CreER $\left.{ }^{+/-} ; M d m 2^{\text {flox/flox }}\right)$ mice $(\mathrm{n}=8,9)(\mathrm{F}) .(\mathrm{G})$ Systolic blood pressure $(\mathrm{sBP})$ or diastolic blood pressure (dBP) of the indicated mice $(n=6,5)$. Data were analyzed by the two-tailed Student's t-test (B, G), or repeated measures ANOVA followed by Tukey's multiple comparison test $(\mathrm{C}-\mathrm{F}) . * \mathrm{P}<0.05 ; * * \mathrm{P}<0.01$, $* * * \mathrm{P}<0.001$. Values represent the mean \pm SEM. NS = not significant. 
Figure 1

A

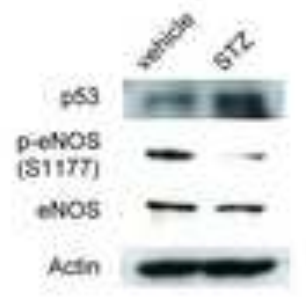

B

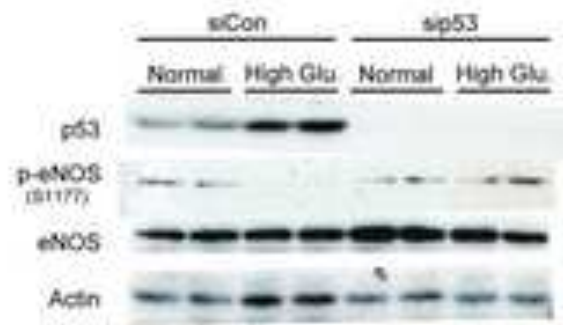

C

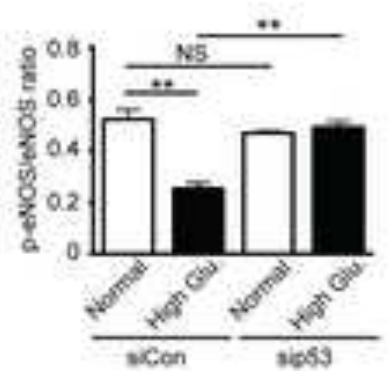

D

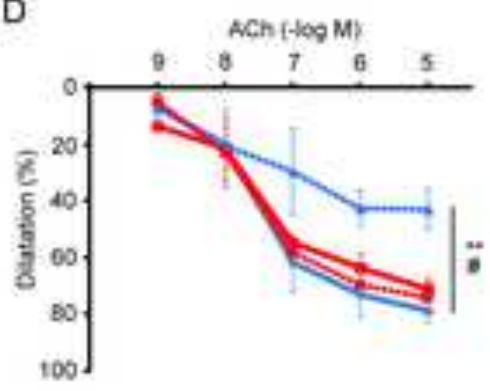

E

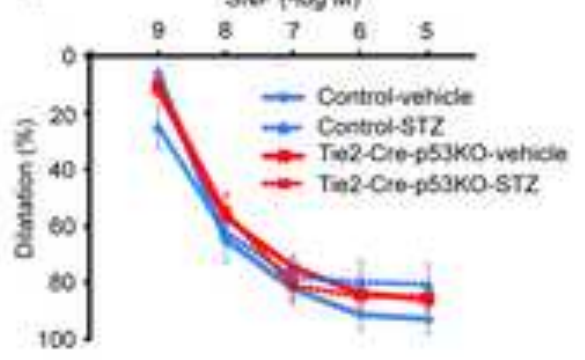

F
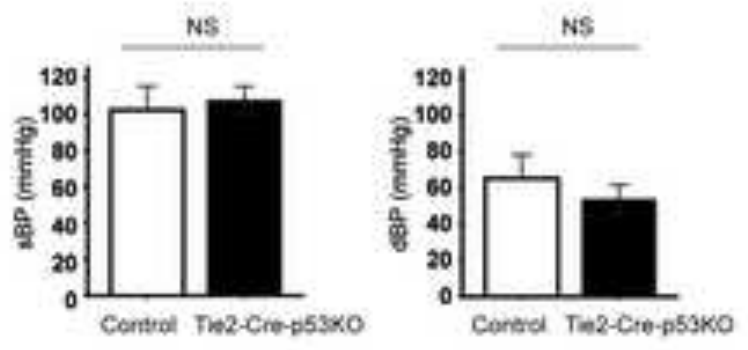

G

$\operatorname{ACh}(\operatorname{sog} M)$

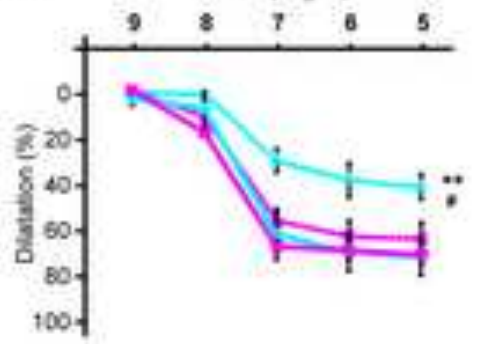

H

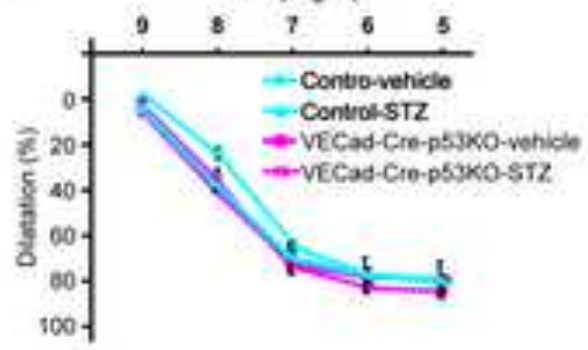

I

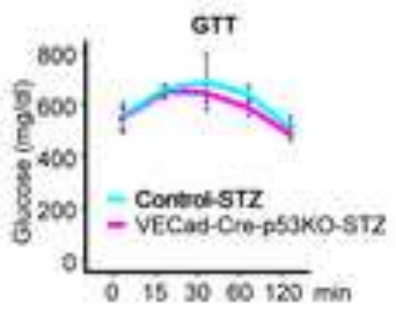


Figure 2
Click here to download high resolution image

Figure 2

A

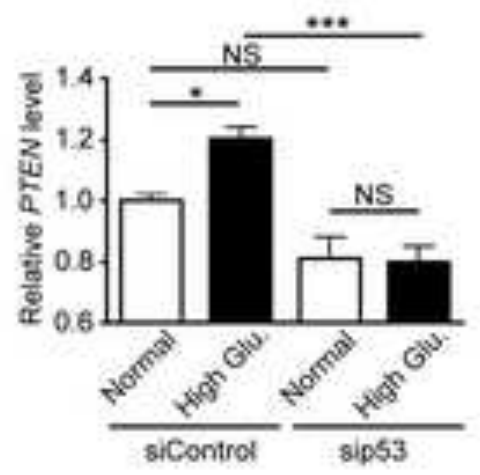

B

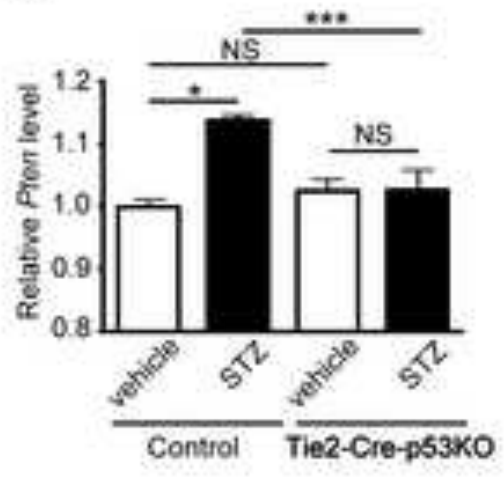

D

C

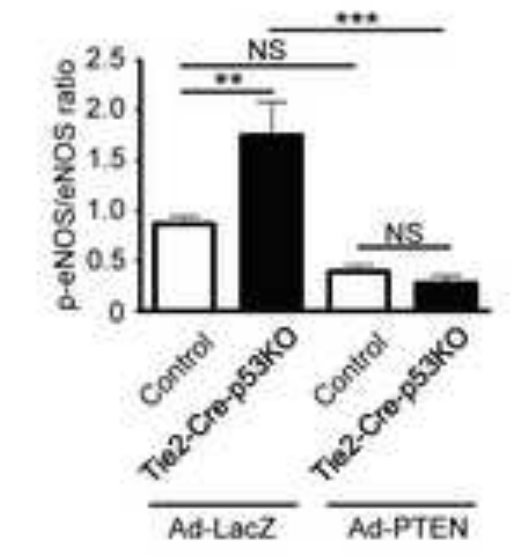

E
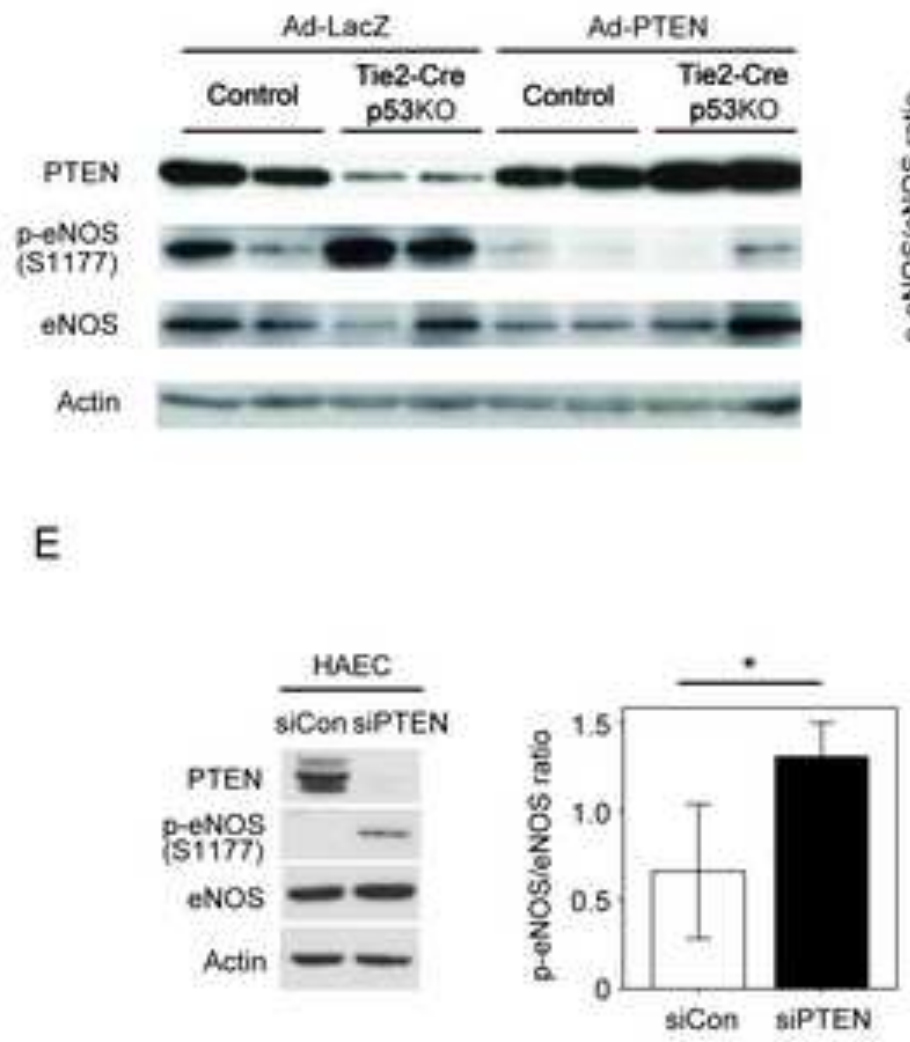

$\mathrm{F}$

G
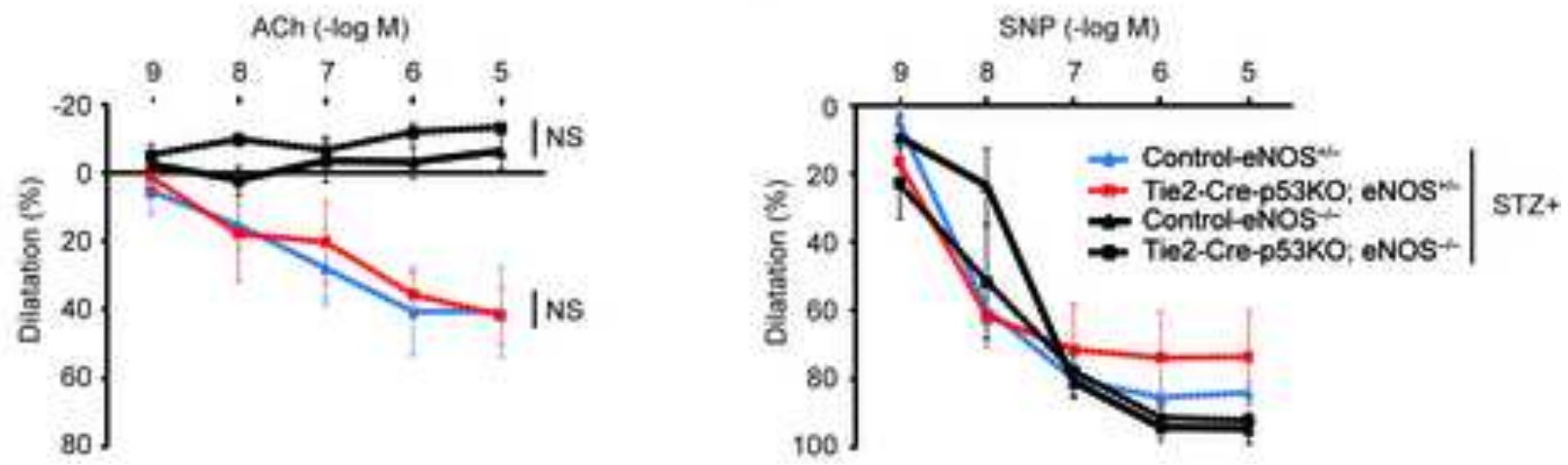
Click here to download high resolution image

Figure 3

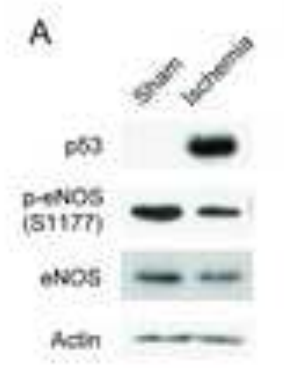

B

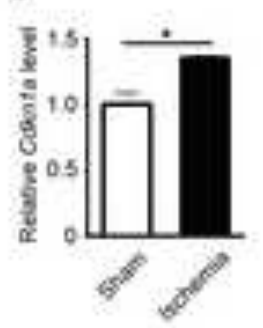

E

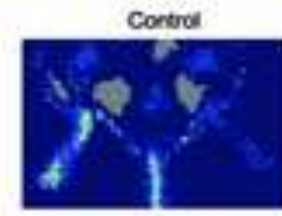

Control - eNOS

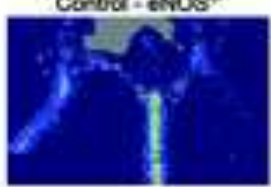

C

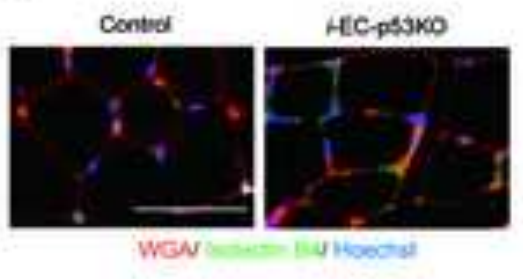

F

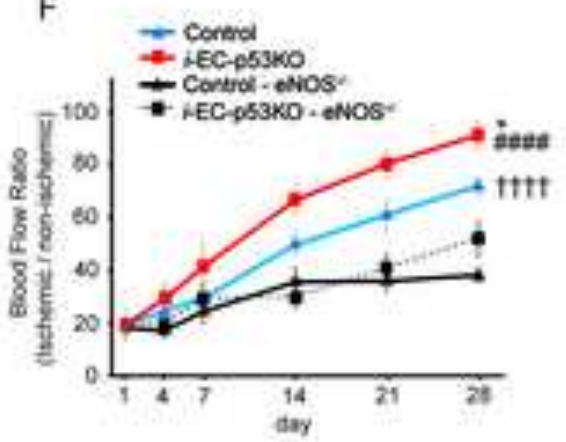

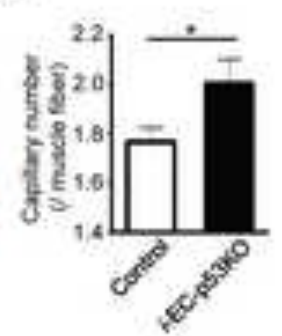

HeCossiko

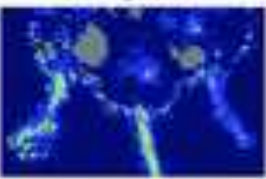

HEC-p53\%o- Atios:

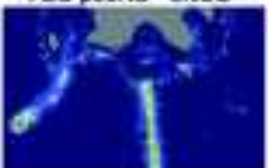


Click here to download high resolution image

Figure 4

A

B
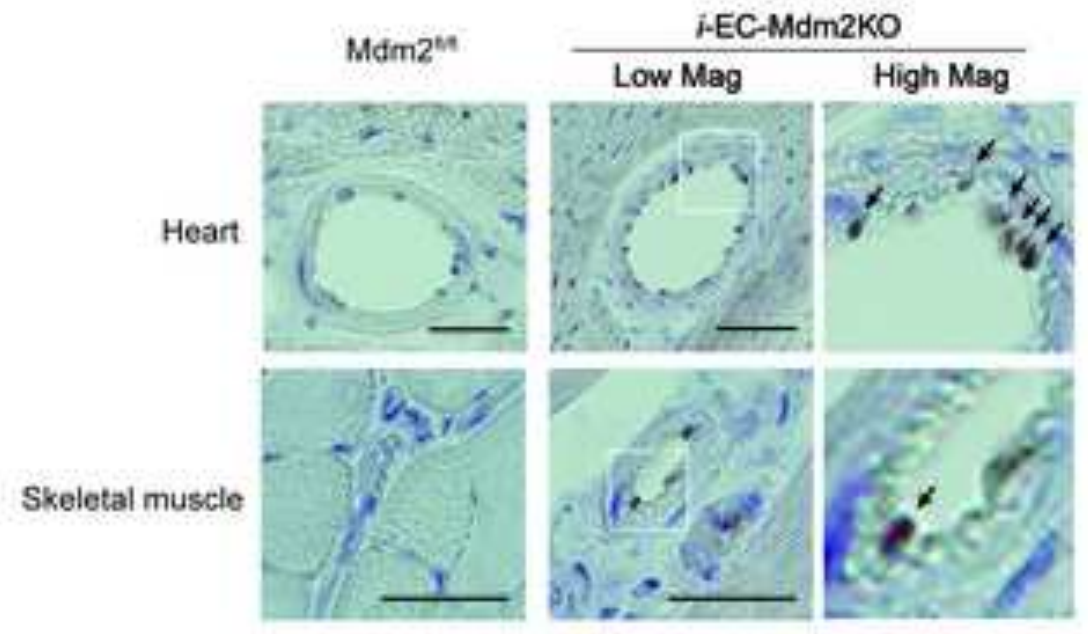

Mdm2 $2^{\text {tet }}$-EC-Mdm2KO

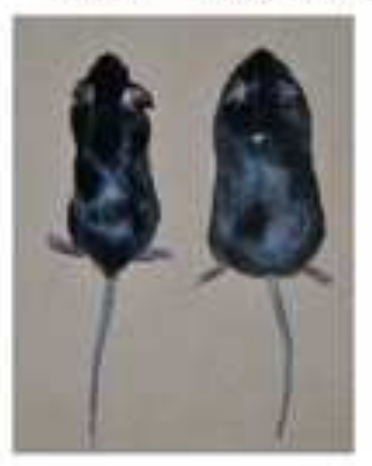

C
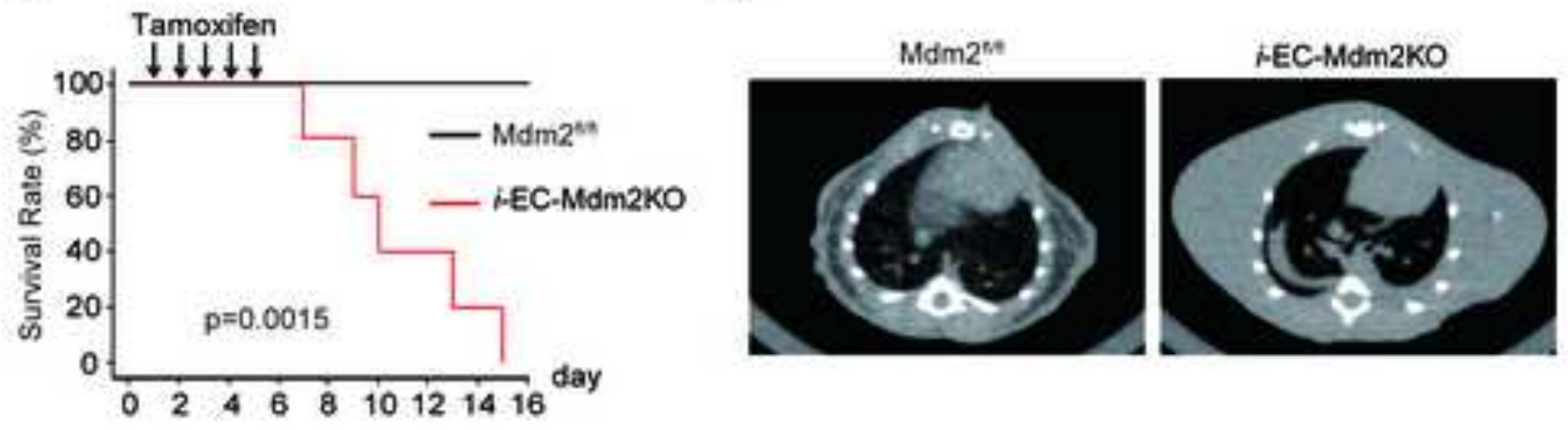

E

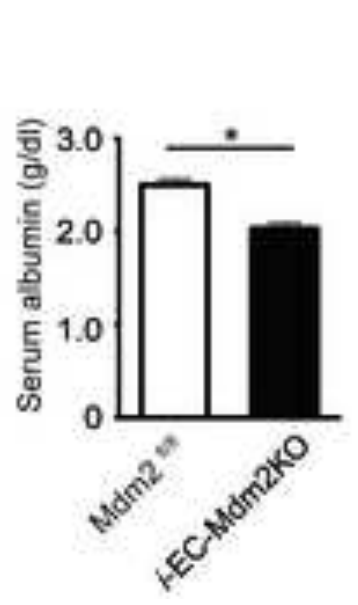

$\mathrm{F}$

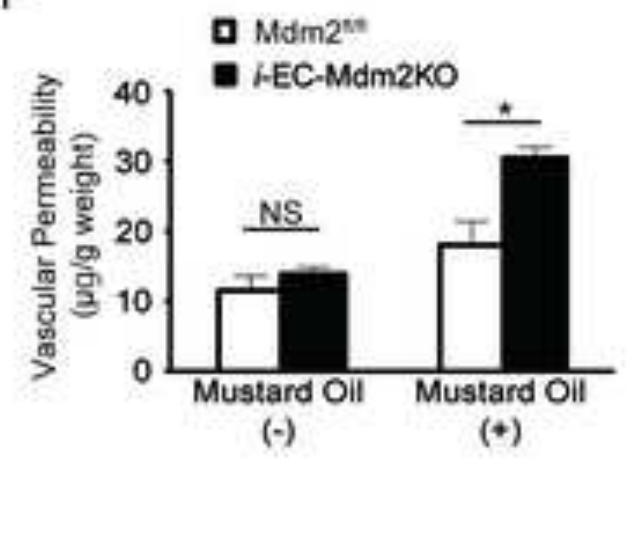

G

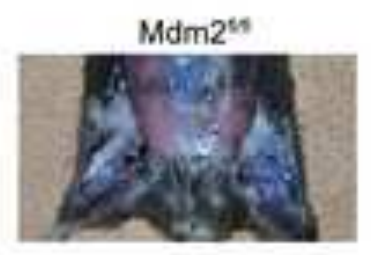

$$
\text { i-EC-Mdm2KO }
$$

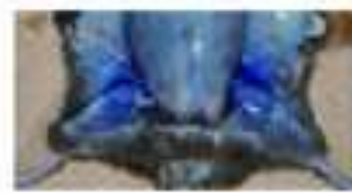




\section{Figure 5}

Click here to download high resolution image

Figure 5

A

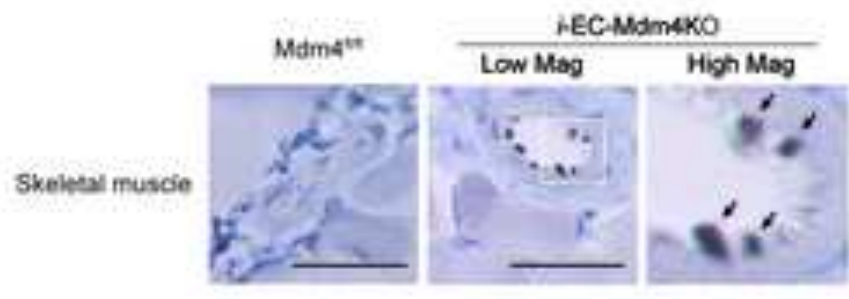

B

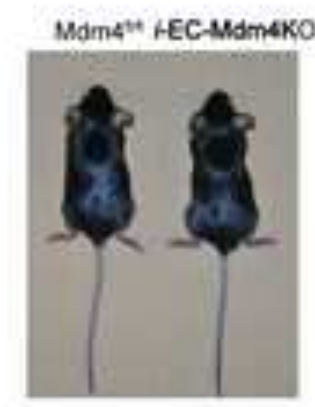

C

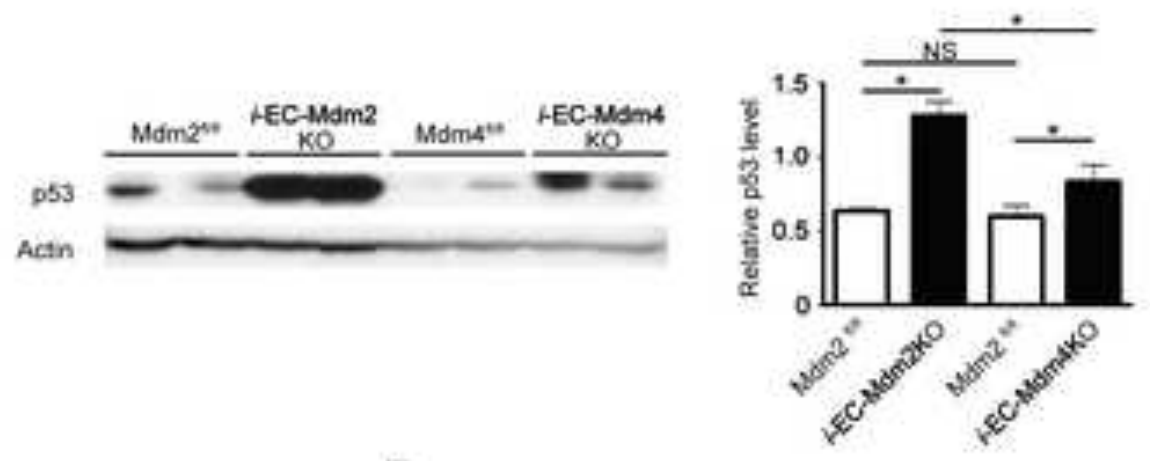

D

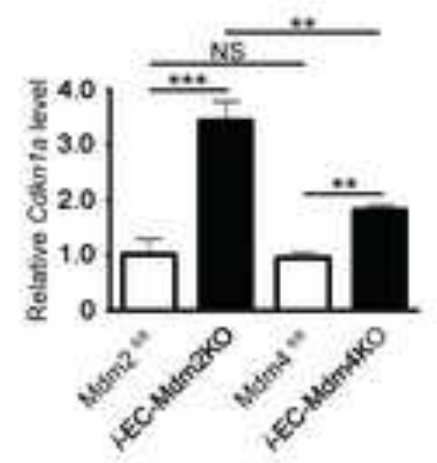

F

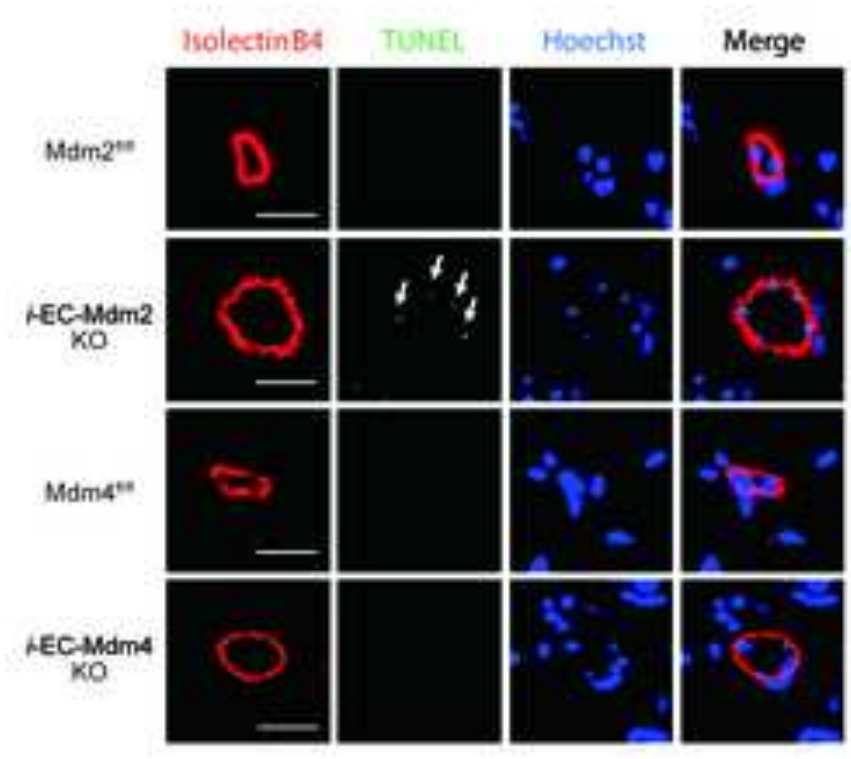

G
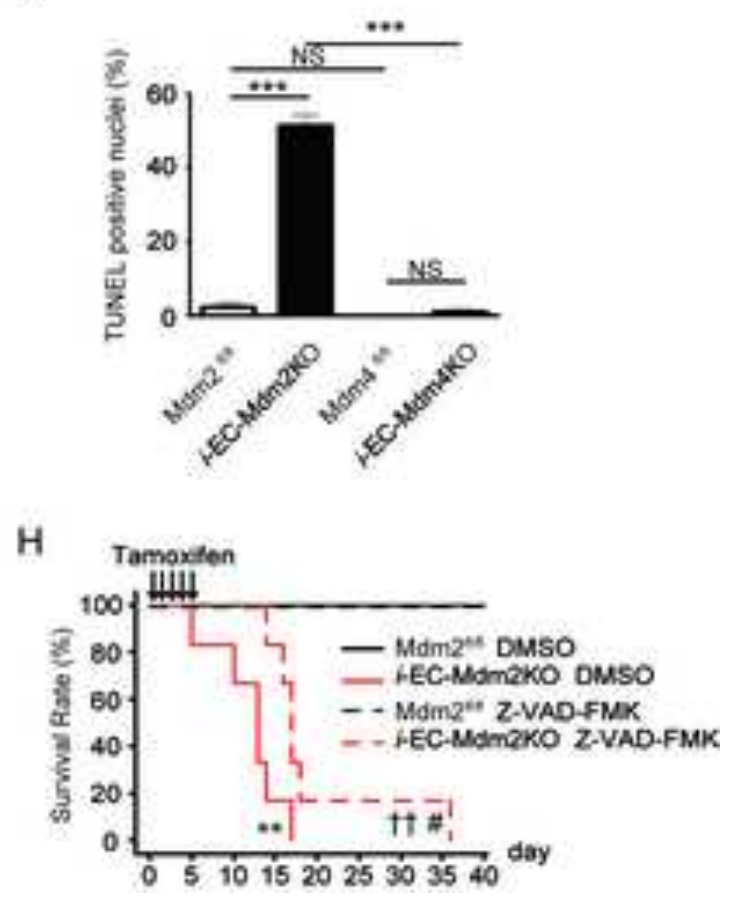
Click here to download high resolution image

Figure 6

A

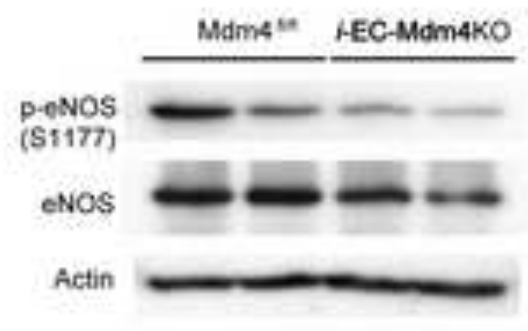

C

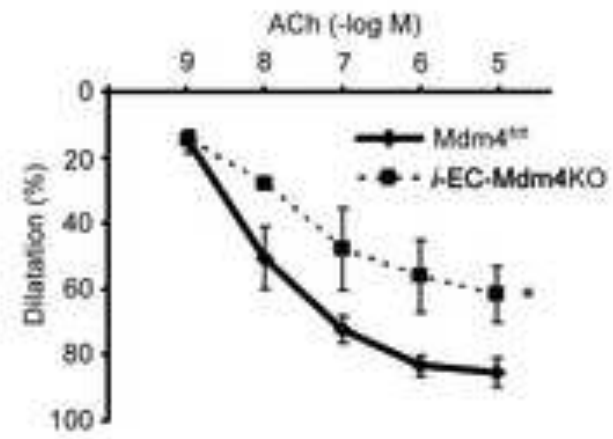

E

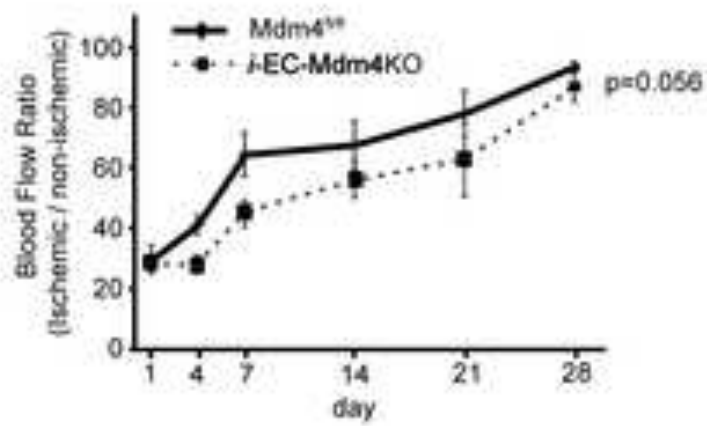

G
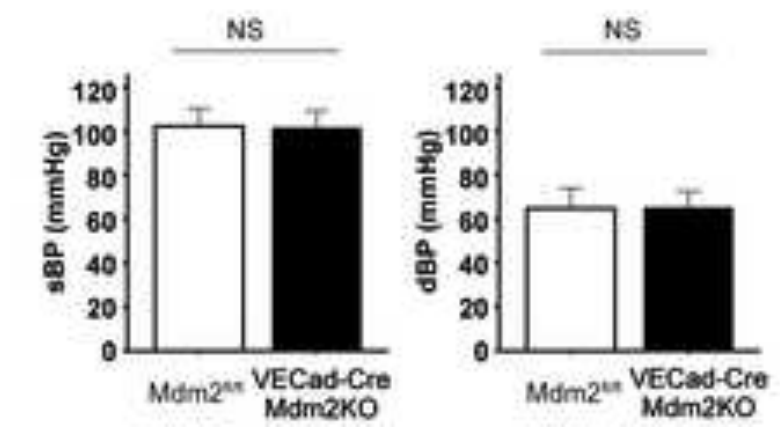

G
B

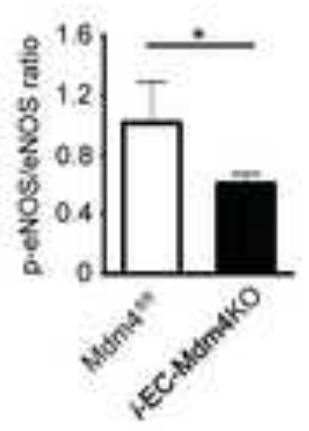

D

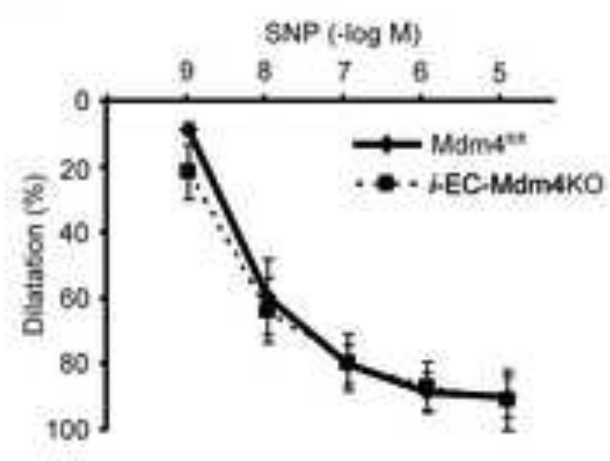

F

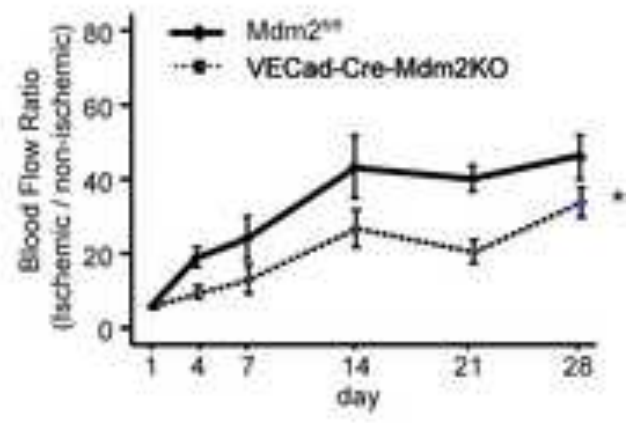




\title{
SUPPLEMENTAL MATERIAL
}

\section{p53 plays a crucial role in endothelial dysfunction associated with hyperglycemia and ischemia}

Short title: p53 in endothelial function

\begin{abstract}
Masataka Yokoyama $^{1 *}$, Ippei Shimizu ${ }^{2,3 *}$, Ayako Nagasawa ${ }^{2,4 *}, Y_{\text {ohko Yoshida }}^{2,3}$, Goro Katsuumi ${ }^{2}$, Takayuki Wakasugi ${ }^{2}$, Yuka Hayashi², Ryutaro Ikegami ${ }^{2}$, Masayoshi Suda $^{2}$, Yusuke Ota ${ }^{2}$, Sho Okada ${ }^{1}$, Marcus Fruttiger ${ }^{5}$, Yoshio Kobayashi ${ }^{1}$, Masanori Tsuchida $^{4}$, Yoshiaki Kubota ${ }^{6}$, and Tohru Minamino ${ }^{2 * *}$
\end{abstract}

${ }^{1}$ Department of Cardiovascular Medicine, Chiba University Graduate School of Medicine, Chiba 260-8670, Japan

${ }^{2}$ Department of Cardiovascular Biology and Medicine, Niigata University Graduate School of Medical and Dental Sciences, Niigata 951-8510, Japan

${ }^{3}$ Division of Molecular Aging and Cell Biology, Niigata University Graduate School of Medical and Dental Sciences, Niigata 951-8510, Japan

${ }^{4}$ Department of Thoracic and Cardiovascular Surgery, Niigata University Graduate School of Medical and Dental Sciences, Niigata 951-8510, Japan

${ }^{5}$ Institute of Ophthalmology, University College London, London EC1V 9EL, UK

${ }^{6}$ Department of Vascular Biology, School of Medicine, Keio University, Tokyo 160-8582, Japan 


\section{Detailed Methods}

\section{Animal models}

All animal study protocols were approved by the Chiba University and Niigata University review board. C57BL/6 mice were purchased from SLC Japan (Shizuoka, Japan). Mice expressing Cre recombinase in endothelial cells (Tie2-Cre) were purchased from Jackson Laboratories. We then crossed Tie2-Cre mice (with a C57BL/6 background) and mice carrying floxed Trp53 alleles (with a C57BL/6 background) [1] to generate mice with endothelial cell-specific knockout of p53, which were used in this study at 12-14 weeks old. To inhibit NOS activity, we crossed endothelial cell-specific p53 knockout mice with eNOS knockout mice purchased from Jackson Laboratories to establish endothelial cellspecific p53/eNOS double knockout mice. We also crossed Pdgfb-Cre-ER mice (with a C57BL/6 background)[2] and mice carrying floxed Trp53 alleles, floxed $M d m 2$ alleles (with a C57BL/6 background)[3], or floxed Mdm4 alleles (with a C57BL/6 background)[4] to generate other endothelial cell-specific p53 knockout mice, endothelial cell-specific Mdm2 knockout mice, and endothelial cell-specific Mdm4 knockout mice, respectively. The mice carrying floxed $M d m 2$ alleles or floxed $M d m 4$ alleles were kindly provided by Professor Guillermina Lozano (The University of Texas MD Anderson Cancer Center). These mutant mice received tamoxifen (Sigma, USA) at a dose of $10 \mathrm{mg}$ $\mathrm{kg}^{-1}$ intraperitoneally once a day for 5 days at 8 weeks of age to induce Cre-mediated recombination. We also generated endothelial cell-specific p53 or Mdm2 knockout mice by crossing VE cadherin-BAC-CreERT2 mice [5, 6] with mice carrying floxed Trp53 alleles or floxed $M d m 2$ alleles. Injection of tamoxifen was performed at $1 \mathrm{mg}$ daily for 5 days in VE cadherin-BAC-CreERT2-p53 KO mice or a single dose of $1 \mathrm{mg}$ in VE cadherin-BAC-CreERT2-Mdm2 KO mice. To induce diabetes, mice were given an intraperitoneal injection of streptozotocin (STZ) in $0.1 \mathrm{M}$ sodium citrate $(\mathrm{pH} \mathrm{4.5)}$ at a dose of $50 \mathrm{mg} / \mathrm{kg}$ daily for 5 days. At 4 weeks after STZ treatment, blood glucose levels were measured with a Gulutest Mint (Sanwakagakukenkyusyo, Japan) to confirm the 
induction of diabetes. To inhibit apoptosis, mice were treated with a pan-caspase inhibitor (Z-VAD-FMK at $3 \mathrm{mg} / \mathrm{kg}$ intraperitoneally every day, Biovision) dissolved in $0.1 \%$ DMSO.

\section{Cell culture}

Human umbilical vein endothelial cells (HUVECs) were cultured in EBM-2 medium (Lonza, Switzerland) with 2\% FBS, growth factors (hEGF, hFGF-B, VEGF, and R3-IGF1), heparin, hydrocortisone, ascorbic acid, and antibiotics $(50 \mathrm{mg} / \mathrm{ml}$ gentamicin and 50 $\mu \mathrm{g} / \mathrm{ml}$ amphotericin B). To examine the effects of exposure to high glucose, HUVECs were cultured for 24 hours in growth factor-free medium with $30 \mathrm{mM}$ glucose and were harvested after stimulation with growth factors for 10 minutes. As the control, $5 \mathrm{mM}$ glucose was added to basal medium and D-mannitol was also added to adjust the osmolality. In addition, human aortic endothelial cells were purchased from Lonza (CC2535) and were cultured according to the manufacturer's instructions.

\section{Gene transduction}

Small-interfering RNA (siRNA) targeting p53 (Invitrogen, BLOCK-iT RNAi Designer, No.1299003) or PTEN (Thermo, Primer Set PTEN Human1 (PTENHSS183790, PTENHSS183791, PTENHSS183792)) was introduced into human endothelial cells by using Lipofectamine RNAiMax (Invitrogen) according to the manufacturer's instructions. High-titer adenoviral stocks $\left(10^{9} \mathrm{pfu}\right)$ were generated with the Adeno-X Expression System (Clontech) according to the manufacturer's instructions. In the in vitro gene transduction experiments, HUVECs were infected with the adenoviral vector encoding human p53 or LacZ (at 20 multiplicities of infection). In the in vivo gene transduction experiments, aortas of mice were infected with the adenoviral vector encoding human PTEN or LacZ $\left(10^{8} \mathrm{pfu}\right.$ in $\left.250 \mu \mathrm{l}\right)$ [7]. In brief, after each mouse was anesthetized with isoflurane, the aorta was ligated at the level of the celiac artery and at the bilateral femoral 
arteries to create a semi-closed intravascular space. Then serum containing the adenovirus was infused into this space using a 30-guage needle, and the injection site was closed with adhesive (Aron Alpha A "Sankyo", Toagosei, Japan). The ligatures were removed after 1 hour, and the treated part of the aorta was harvested after another 1 hour.

\section{Vascular reactivity assay}

After mice were anesthetized, the iliac arteries were removed and mounted on a pressure myograph (DMT, Asrhus, Denmark). Then vascular reactivity was measured as described previously [8]. The vessels were maintained at $100 \mathrm{mmHg}$ pressure and $37^{\circ} \mathrm{C}$, and were perfused with physiological saline (PSS) having the following composition: $118.99 \mathrm{mM}$ $\mathrm{NaCl}, 4.69 \mathrm{mM} \mathrm{KCl}, 1.17 \mathrm{mM} \mathrm{MgSO}_{4}, 25 \mathrm{mM} \mathrm{NaHCO} 3,2.5 \mathrm{mM} \mathrm{CaCl}_{2}, 1.18 \mathrm{mM}$ $\mathrm{KH}_{2} \mathrm{PO}_{4}, 0.03 \mathrm{mM}$ EDTA, and $5.5 \mathrm{mM}$ glucose. The PSS was aerated with $95 \% \mathrm{O}_{2}$ and $5 \% \mathrm{CO}_{2}$ to maintain a $\mathrm{pH}$ of 7.4. Vessels were equilibrated for 15-30 minutes, followed by constriction with $10^{-5} \mathrm{M}$ phenylephrine. Then response curves were generated by stepwise addition of increasing concentrations of acetylcholine (Ach) from $10^{-9}$ to $10^{-5} \mathrm{M}$ to the organ bath. Subsequently, the vessels were washed with PSS and constricted with $10^{-5} \mathrm{M}$ phenylephrine again. To further test endothelium-independent vasodilatation, basal NO production was inhibited by addition of 1-NAME $\left(3 \times 10^{-4} \mathrm{M}, 30\right.$ minutes $)$. Then dose-response curves for sodium nitroprusside (SNP) were generated by stepwise addition of increasing concentrations of SNP from $10^{-9}$ to $10^{-5} \mathrm{M}$. The relaxation responses to Ach and SNP were expressed as the percent change of force $(\mathrm{mN})$ using the following equation: percent dilation $=100 \% \times\left\{1-\left(\right.\right.$ Force $_{\text {after Ach } / \mathrm{SNP}}-$ Force $\left._{\text {basal }}\right) /($ Force initial diameter following phenylephrine - Force basal) $\}$.

\section{Hind limb ischemia model}

Mice were anesthetized with pentobarbital $(50 \mathrm{mg} / \mathrm{kg})$ and then the proximal part of the femoral artery and the distal part of the popliteal artery were ligated and stripped out after 
dissection of all side branches, as described previously [9]. (For assessment of ischemic vessels, the ligated arteries were not stripped and were harvested after 24 hours.) Then the recovery of blood flow was assessed until 28 days after surgery. Hind limb perfusion was measured with a laser Doppler perfusion analyzer (Moor Instruments, Devon, UK) during $0.5 \%$ isoflurane anesthesia with $3 \mathrm{~L} / \mathrm{min} \mathrm{O}_{2}$. Samples for histologic examination were harvested from the ischemic limb on day 10 after surgery.

\section{Physiological analyses}

Echocardiography was performed with a Vevo 770 High-Resolution Imaging System (Visual Sonic Inc., Toronto, Canada). The heart rate was maintained at 500-600 bpm to minimize deviation of the data when cardiac function was assessed by the area-length method. After mice were anesthetized with pentobarbital $(50 \mathrm{mg} / \mathrm{kg})$, we performed CT scanning (LaTheta, Aloka, Tokyo, Japan) at 2-mm slice intervals from the diaphragm to the base of the abdominal cavity according to the manufacturer's protocol. A tail-cuff system (BP-98A, Softron Co., Tokyo, Japan) was used to measure arterial blood pressure.

\section{Vascular permeability assay}

Evans blue dye (30 mg/kg in $100 \mu \mathrm{l}$ of saline; Sigma) was injected into the tail veins of mice and leakage of plasma induced by mustard oil was measured as described previously [10]. Mustard oil (diluted to $5 \%$ in mineral oil) was applied to the dorsal and ventral surfaces of the ear with a cotton swab at 1 minute after dye injection and application was repeated 15 minutes later. Photographs were taken 30 minutes after the injection of Evans blue dye. The ears were harvested and dye was extracted with $1 \mathrm{ml}$ of formamide overnight at $55^{\circ} \mathrm{C}$, followed by measurement of the absorbance at $600 \mathrm{~nm}$. Dye leakage from subcutaneous vessels was evaluated at 2 hours after injection with the animal under anesthesia. 


\section{Laboratory tests}

Blood was collected from the tail veins of mice and blood glucose levels were measured with a Glutest Mint (Sanwa Kagaku Kenkyusho, Nagoya, Japan). Intraperitoneal glucose tolerance test (IGTT) was done as previously described [11] with slight modification and glucose was intraperitoneally given at a dose of $1 \mathrm{~g} \mathrm{~kg}^{-1}$ (body weight). Albumin levels in serum, urine, and pleural fluid were measured by the Nagahama Life Science Laboratory of Oriental Yeast Co. Ltd. according to their protocol.

\section{RNA analysis}

For real-time PCR, total RNA was isolated from tissues or cells with RNAZol-B (Molecular Research Center) and complementary DNA was prepared using a QuiantiTect Reverse Transcription kit (QIAGEN). Quantitative real-time PCR was performed by using a LightCycler (Roche) with the Taqman Universal Probe Library and Light Cycler Master (Roche) according to the manufacturer's instructions. Data were analyzed by the $2^{-1 \Delta \Delta \mathrm{CT}}$ method. The primers and their sequences were as follows. RPLPO or Rplp0 was used as the internal control.

Human

PTEN; 5'-GGGGAAGTAAGGACCAGAGAC-3', 5'-TCCAGATGATTCTTTAACAGGTAGC-3'

RPLP0; 5'-CGACAATGGCAGCATCTACA-3', 5'-TGATGCAACAGTTGGGTAGC-3'

Mouse

Pten; 5'-AGGCACAAGAGGCCCTAGAT-3', 5'-CTGACTGGGAATTGTGACTCC-3'

Bax; 5'-GTGAGCGGCTGCTTGTCT-3', 5'-GGTCCCGAAGTAGGAGAGGA-3'

Cdknla; 5'-TCCACAGCGATATCCAGACA-3', 5'-GGACATCACCAGGATTGGAC-3'

Rplp0; 5'-GATGCCCAGGGAAGACAG-3', 5'-ACAATGAAGCATTTTGGATAATCA-3'

\section{Western blot analysis}

Whole-cell lysates $(30-50 \mu \mathrm{g})$ were resolved by SDS polyacrylamide gel electrophoresis 
(PAGE). Proteins were transferred to a polyvinylidene difluoride (PVDF) membrane (Millipore) and were incubated with the following primary antibodies: anti-p53 antibody (sc-126, Santa Cruz) for HUVEC, anti-p53 antibody (\#2524, Cell Signaling) for mouse samples, anti-eNOS antibody (610296, BD Transduction Laboratories), anti-phosphoeNOS (Ser 1177) antibody (\#9571, Cell Signaling), anti-Akt antibody (\#9272, Cell Signaling), anti-phospho-Akt (Ser 473) antibody (\#9271, Cell Signaling), anti-PTEN antibody (\#9559, Cell Signaling), anti-actin antibody (Sigma A5060, or cell signaling \#4970). Immunoglobulin G (IgG)-specific horseradish peroxidase antibodies (anti-mouse, anti-rabbit, and anti-goat; Jackson) were used as the secondary antibodies. For detection of mouse p53, a specific anti-mouse light chain antibody (Jackson) was used as the secondary antibody to avoid detecting the IgG heavy chain $(50 \mathrm{kDa})$. Actin was used as an equal loading control. Specific proteins were detected by the enhanced chemiluminescence method (Amersham), and quantitative analysis of protein levels was done with Image J software.

\section{Histological examination}

Samples of various tissues, such as the aorta, heart, and skeletal muscles, were harvested from mice and fixed in $10 \%$ formalin overnight. Then the samples were embedded in paraffin and sectioned for immunohistochemistry. After antigen retrieval by incubation in $0.01 \mathrm{M}$ citrate-buffer solutions for 15 minutes at $121^{\circ} \mathrm{C}$, endothelial $\mathrm{p} 53$ protein was detected with an anti-p53 antibody (CM5, Novocastra) and HRP-conjugated dextran polymer (EnVision+, Dako). Sections were incubated in Isolectin IB4 (I21414, Invitrogen) and Streptavidin-Alexa568 (S11226, Invitrogen) for staining of endothelial cells, and in WGA-lectin conjugated with FITC (Sigma) for staining of muscle membranes. Vascular density was calculated from the number of IB4-positive cells per muscle fiber. Apoptosis was detected by the terminal deoxy nucleotidyl transferasemediated dUTP-biotin nick end labeling (TUNEL) method (In Situ Cell Death Detection 
Kit, Fluorescein; Roche) with an Alexa Fluor 488 labeled anti-fluorescein antibody (A11096, Molecular Probes) to enhance the green signal.

\section{Statistical analysis}

Results are shown as the mean \pm S.E.M. Differences between groups were examined by the two-tailed Student's t-test or ANOVA, followed by Bonferroni's correction or Tukey's multiple comparison test for comparison of mean values. Survival curves were calculated by the Kaplan-Meier method and were compared with the log-rank test. Some data were analyzed with repeated measures ANOVA, followed by Tukey's multiple comparison test. In all analyses, $\mathrm{P}<0.05$ was considered to indicate statistical significance. Statistical analyses were done with SPSS version 24 or Prism7 software. 


\section{Supplemental Figures and Figure Legends}

A

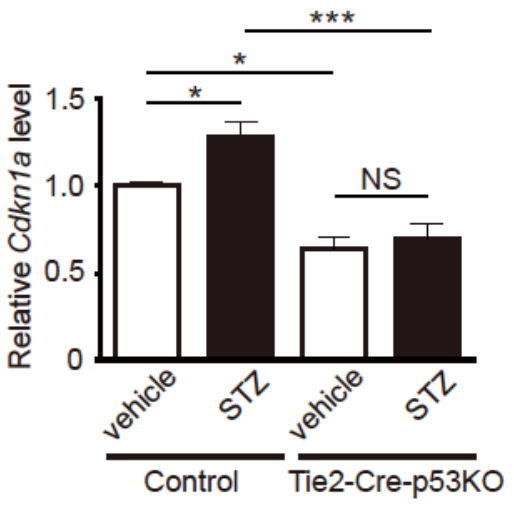

$\mathrm{B}$

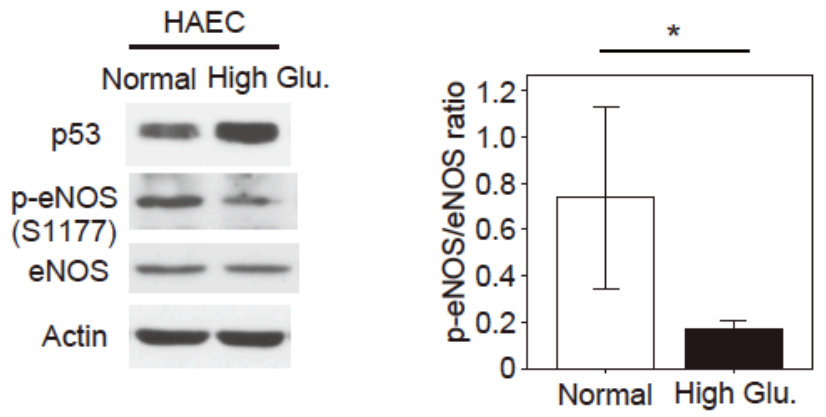

C

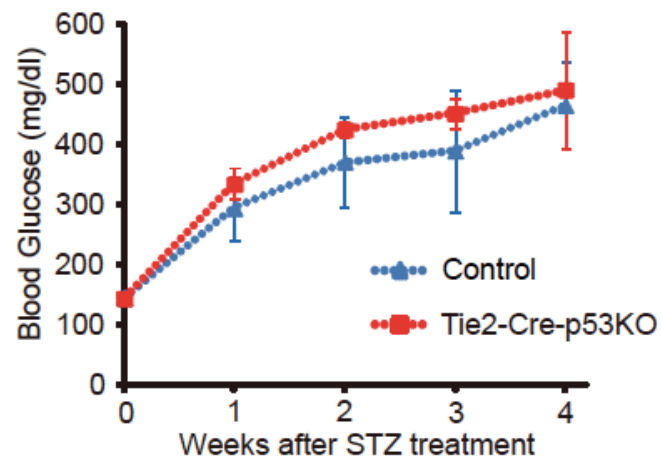

Supplemental Figure 1 Expression of Cdkn1a in aorta and time course of glucose levels of EC-p53KO mice after STZ treatment

(A) Real-time PCR assessing the expression of Cdkn1a (p21) in the aorta of Tie2-Crep53KO mice and littermate control (Control) administrated vehicle saline (vehicle) or streptozotocin (STZ) $(n=3)$. (B) Expression of p53, phospho-eNOS (p-eNOS), and eNOS was examined by western blotting in human aortic endothelial cells (HAEC) under a normal or high glucose condition (High Glu). Right panel indicates the quantification $(n=8,7)$. For this study, an outlier ( $n=1$ in the normal group) and abnormal values $(n=2$ in the high glucose group) were excluded by boxplot (SPSS) for further statistical analysis. (C) Blood glucose levels of Tie2-Cre-p53KO mice and littermate control (Control) were measured after STZ treatment $(n=4)$. Data were analyzed by 2 -way ANOVA followed by Bonferroni's correction (A), by the 2-tailed Student's t-test (B), or repeated measures followed by Tukey's multiple comparison test $(\mathrm{C}) .{ }^{*} \mathrm{P}<0.05 ; * * \mathrm{P}<0.01,{ }^{*} * \mathrm{P}<0.001$. Values represent the mean $\pm \mathrm{SEM}$. NS $=$ not significant. 
A

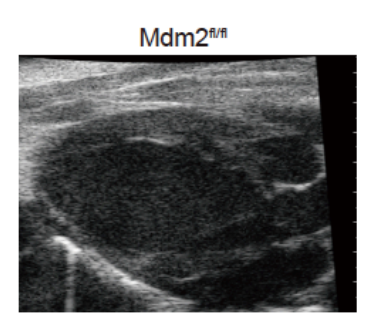

C

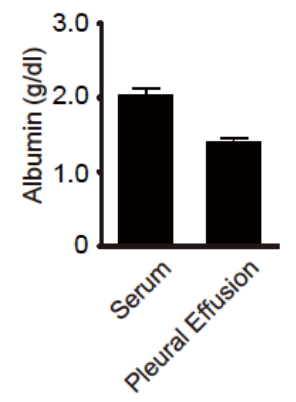

$\mathrm{B}$
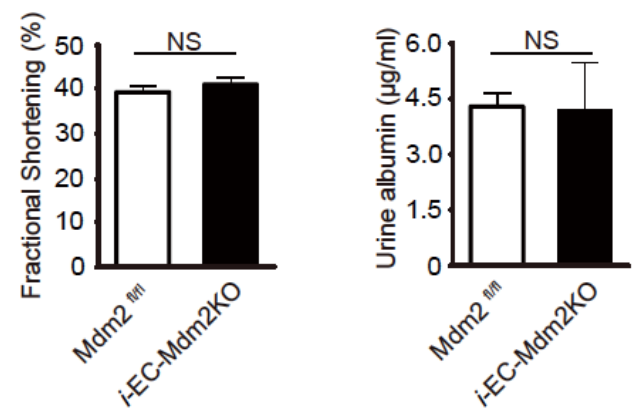

$\mathrm{D}$

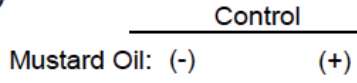

i-EC-Mdm2KO

$(-)$

$(+)$

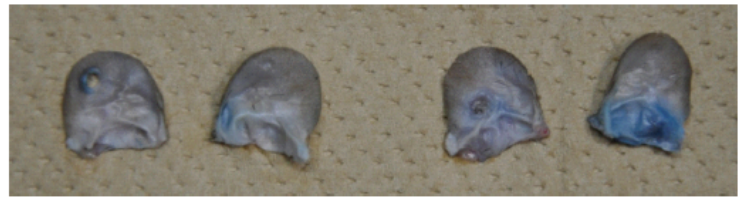

Supplemental Figure 2 Echocardiography and albumin leakage assessment of i-ECMdm2KO mice.

(A) Echocardiographic images of i-EC-Mdm2KO mouse (Pdgfb-Cre-ER ${ }^{+/-} ; M d m 2^{\text {flox/flox }}$ ) and $M d m 2^{\text {flox/flox }}$ mouse 10 days after tamoxifen-induced gene deletion. The graph shows the percentage of fraction shortening in these mice $(n=3)$. (B) Urine albumin levels of mice in Supplemental Fig. 2A $(n=3)$. (C) The albumin levels in serum and pleural effusion of $\mathrm{i}-\mathrm{EC}-\mathrm{Mdm} 2 \mathrm{KO}$ mice (n=3). (D) The ear lobes of i-EC-Mdm2KO mouse and $M d m 2^{\text {flox/flox }}$ mouse 30 minutes after injection of Evans blue dye. Data were analyzed by the 2-tailed Student's t-test (A, B). Data are shown as the means \pm S.E.M. NS $=$ not significant. 


\section{Supplemental References}

[1] S. Marino, M. Vooijs, H. van Der Gulden, J. Jonkers, A. Berns, Induction of medulloblastomas in p53null mutant mice by somatic inactivation of $\mathrm{Rb}$ in the external granular layer cells of the cerebellum, Genes Dev 14(8) (2000) 994-1004.

[2] S. Claxton, V. Kostourou, S. Jadeja, P. Chambon, K. Hodivala-Dilke, M. Fruttiger, Efficient, inducible Cre-recombinase activation in vascular endothelium, Genesis 46(2) (2008) 74-80.

[3] J.D. Grier, W. Yan, G. Lozano, Conditional allele of mdm2 which encodes a p53 inhibitor, Genesis 32(2) (2002) 145-7.

[4] J.D. Grier, S. Xiong, A.C. Elizondo-Fraire, J.M. Parant, G. Lozano, Tissue-specific differences of p53 inhibition by Mdm2 and Mdm4, Mol Cell Biol 26(1) (2006) 192-8.

[5] K. Okabe, S. Kobayashi, T. Yamada, T. Kurihara, I. Tai-Nagara, T. Miyamoto, Y.S. Mukouyama, T.N. Sato, T. Suda, M. Ema, Y. Kubota, Neurons Limit Angiogenesis by Titrating VEGF in Retina, Cell 159(3) (2014) 584-596.

[6] S. Si, Y. Nakajima-Takagi, T. Iga, M. Tsuji, L. Hou, M. Oshima, S. Koide, A. Saraya, S. Yamazaki, K. Takubo, Y. Kubota, T. Minamino, A. Iwama, Hematopoietic insults damage bone marrow niche by activating p53 in vascular endothelial cells, Exp Hematol 63 (2018) 41-51 e1.

[7] M.Y. Alexander, M.J. Brosnan, C.A. Hamilton, P. Downie, A.M. Devlin, F. Dowell, W. Martin, H.M. Prentice, T. O'Brien, A.F. Dominiczak, Gene transfer of endothelial nitric oxide synthase improves nitric oxide-dependent endothelial function in a hypertensive rat model, Cardiovascular research 43(3) (1999) 798-807.

[8] D.N. Atochin, A. Wang, V.W. Liu, J.D. Critchlow, A.P. Dantas, R. Looft-Wilson, T. Murata, S. Salomone, H.K. Shin, C. Ayata, M.A. Moskowitz, T. Michel, W.C. Sessa, P.L. Huang, The phosphorylation state of eNOS modulates vascular reactivity and outcome of cerebral ischemia in vivo, J Clin Invest 117(7) (2007) 1961-7.

[9] J. Moriya, T. Minamino, K. Tateno, S. Okada, A. Uemura, I. Shimizu, M. Yokoyama, A. Nojima, M. Okada, H. Koga, I. Komuro, Inhibition of semaphorin as a novel strategy for therapeutic angiogenesis, Circulation research 106(2) 391-8.

[10] E.D. Han, R.C. MacFarlane, A.N. Mulligan, J. Scafidi, A.E. Davis, 3rd, Increased vascular permeability in C1 inhibitor-deficient mice mediated by the bradykinin type 2 receptor, J Clin Invest 109(8) (2002) 1057-63.

[11] I. Shimizu, Y. Yoshida, T. Katsuno, K. Tateno, S. Okada, J. Moriya, M. Yokoyama, A. Nojima, T. Ito, R. Zechner, I. Komuro, Y. Kobayashi, T. Minamino, p53-induced adipose tissue inflammation is critically involved in the development of insulin resistance in heart failure, Cell Metab 15(1) (2012) 51-64. 